OPEN ACCESS

Edited by:

Rachel Amir,

Migal - Galilee Research Institute,

Israel

Reviewed by:

Markus Wirtz,

Universität Heidelberg, Germany

Irene García,

Institute of Plant Biochemistry

and Photosynthesis (IBVF), Spain

*Correspondence:

Masami Yokota Hirai

masami.hirai@riken.jp

Specialty section:

This article was submitted to

Plant Metabolism

and Chemodiversity,

a section of the journal

Frontiers in Plant Science

Received: 18 December 2020

Accepted: 17 March 2021

Published: 07 May 2021

Citation:

Watanabe M, Chiba Y and

Hirai MY (2021) Metabolism

and Regulatory Functions of O-Acetylserine,

S-Adenosylmethionine,

Homocysteine, and Serine in Plant

Development and Environmental

Responses

Front. Plant Sci. 12:643403 doi: $10.3389 /$ fp/s. 2021.643403

\section{Metabolism and Regulatory Functions of $O$-Acetylserine, S-Adenosylmethionine, Homocysteine, and Serine in Plant Development and Environmental Responses}

\author{
Mutsumi Watanabe ${ }^{1}$, Yukako Chiba $^{2}$ and Masami Yokota Hirai ${ }^{3,4 *}$ \\ ${ }^{1}$ Graduate School of Biological Science, Nara Institute of Science and Technology, Ikoma, Japan, ${ }^{2}$ Graduate School of Life \\ Sciences, Faculty of Science, Hokkaido University, Sapporo, Japan, ${ }^{3}$ RIKEN Center for Sustainable Resource Science, \\ Yokohama, Japan, ${ }^{4}$ Graduate School of Bioagricultural Sciences, Nagoya University, Nagoya, Japan
}

The metabolism of an organism is closely related to both its internal and external environments. Metabolites can act as signal molecules that regulate the functions of genes and proteins, reflecting the status of these environments. This review discusses the metabolism and regulatory functions of $O$-acetylserine (OAS), S-adenosylmethionine (AdoMet), homocysteine (Hcy), and serine (Ser), which are key metabolites related to sulfur (S)-containing amino acids in plant metabolic networks, in comparison to microbial and animal metabolism. Plants are photosynthetic auxotrophs that have evolved a specific metabolic network different from those in other living organisms. Although amino acids are the building blocks of proteins and common metabolites in all living organisms, their metabolism and regulation in plants have specific features that differ from those in animals and bacteria. In plants, cysteine (Cys), an S-containing amino acid, is synthesized from sulfide and OAS derived from Ser. Methionine (Met), another S-containing amino acid, is also closely related to Ser metabolism because of its thiomethyl moiety. Its $S$ atom is derived from Cys and its methyl group from folates, which are involved in one-carbon metabolism with Ser. One-carbon metabolism is also involved in the biosynthesis of AdoMet, which serves as a methyl donor in the methylation reactions of various biomolecules. Ser is synthesized in three pathways: the phosphorylated pathway found in all organisms and the glycolate and the glycerate pathways, which are specific to plants. Ser metabolism is not only important in Ser supply but also involved in many other functions. Among the metabolites in this network, OAS is known to function as a signal molecule to regulate the expression of OAS gene clusters in response to environmental factors. AdoMet regulates amino acid metabolism at enzymatic and translational levels and regulates gene expression as methyl donor in 
the DNA and histone methylation or after conversion into bioactive molecules such as polyamine and ethylene. Hcy is involved in Met-AdoMet metabolism and can regulate Ser biosynthesis at an enzymatic level. Ser metabolism is involved in development and stress responses. This review aims to summarize the metabolism and regulatory functions of OAS, AdoMet, Hcy, and Ser and compare the available knowledge for plants with that for animals and bacteria and propose a future perspective on plant research.

Keywords: aspartate-family amino acid, homocysteine, O-acetylserine, one-carbon metabolism, serine, S-adenosylmethionine, sulfur assimilation

\section{INTRODUCTION}

Plants (land plants) are photosynthetic auxotrophs that assimilate carbon dioxide and inorganic ions absorbed from the soil into organic compounds. They share common biosynthetic pathways for proteinogenic amino acids with prokaryotic microbes such as Escherichia coli. However, plant metabolism is compartmentalized into several organelles that have specific functions. It also differs from the metabolism of animals, as they consume nutrients through their diet.

Land plants have evolved complex body plans, which require developmental regulation of metabolism. They have also evolved adaptive mechanisms that regulate metabolism to cope with terrestrial environments that are harsher than aquatic environments. To understand why plants have evolved extant metabolic systems, a comparison of these systems with those in other organisms will be helpful. In this review, we aim to summarize commonalities and differences in metabolism related to sulfur (S)-containing amino acids and one-carbon $\left(\mathrm{C}_{1}\right)$ metabolism among plants, bacteria, and animals. The changes in metabolite content are due to metabolic regulation, and the metabolites in turn regulate metabolism. We also elucidate the regulatory functions of metabolites closely related to each other, focusing on four amino acids: $O$-acetylserine (OAS), $S$-adenosylmethionine (AdoMet), homocysteine (Hcy), and serine (Ser) (Table 1).

In the first part of this review, we introduce the metabolism of OAS (section "OAS Is a Key Metabolite in Cys Synthesis"), Hcy (section "Hcy Is Essential for de novo Met Synthesis and AdoMet Recycling"), and AdoMet (section "AdoMet Provides Methyl and Aminopropyl Moieties and Is Recycled in the Three Cycles") in the context of $\mathrm{S}$ assimilation and S-containing amino acid biosynthesis. We also introduce $\mathrm{C}_{1}$ metabolism (section "OneCarbon Metabolism Involves Tetrahydrofolate and AdoMet Metabolism") and Ser metabolism (section "Ser Metabolism Interconnects Metabolic Network"), which are closely related to the metabolism of OAS, Hcy, and AdoMet. The metabolic pathways described in these chapters are overviewed in Figure 1. In the second part, we describe the regulatory control functions of OAS (section "OAS"), AdoMet (section "AdoMet"), Hcy (section "Hcy"), and Ser (section "Ser") in plants in comparison to those of bacteria and animals.

\section{METABOLISM INVOLVING OAS, ADOMET, HCY, AND SER}

\section{OAS Is a Key Metabolite in Cys Synthesis}

S assimilation of inorganic S into organic S in plants, bacteria, and yeast is especially important in nature because animals do not have these assimilatory mechanisms. Animals require methionine (Met) as an essential amino acid because it is a source of nutrient S (Brosnan and Brosnan, 2006). Sulfate is the principal source of $S$ for plants and many bacteria (Leustek et al., 2000; Takahashi et al., 2011). To incorporate the S atom of sulfate into cysteine (Cys), which is the first organic compound with reduced $\mathrm{S}$, the reduction of sulfate to sulfide is required. Plants universally use the adenosine- $5^{\prime}$-phosphate (APS) reductase pathway (Figure 2), whereas bacteria use either the APS reductase (APR) pathway or the $3^{\prime}$-phospho-APS (PAPS) reductase pathway. In plants and sulfate-assimilating bacteria, inorganic sulfate is reduced to APS by ATP sulfurylase (ATPS) and then converted to sulfite by APR, which is reduced to sulfide by sulfite reductase (SiR; Bick et al., 2000). In other bacteria including $E$. coli or in yeast, sulfate is incorporated into APS by ATPS and then converted to PAPS by APS kinase (APK), which is reduced to sulfite by PAPS reductase and subsequently to sulfide by SiR (Masselot and De Robichon-Szulmajste, 1975; Sekowska et al., 2000). The biosynthesis of Cys represents the final step of sulfate assimilation. In bacteria and plants, Cys is synthesized from OAS, which is an activated Ser, by incorporating sulfide into the direct sulfhydrylation pathway (Figure 2 for plants). Ser acetyltransferase (SERAT also called SAT) catalyzes the OAS synthesis from acetyl-CoA and Ser. Synthesized OAS is condensed with sulfide by OAS(thiol)lyase/OAS sulfhydrylase (OAS-TL also called OASS) to form Cys. In yeast, sulfide can be condensed with OAS to produce Cys or with $O$-acetylhomoserine to produce Hcy, which can be converted to cystathionine (CysT) and then to Cys. The budding yeast Saccharomyces cerevisiae has only $\mathrm{O}$-acetylhomoserine pathway, while the fission yeast Schizosaccharomyces pombe has both pathways (Cherest and Surdin-Kerjan, 1992; Marzluf, 1997). Bacteria can also integrate thiosulfate into OAS to produce $S$-sulfocysteine catalyzed by OAS-TL and then Cys (Hulanicka et al., 1979; Nakamura et al., 1984). In bacteria, there are more than 20 genes required for the transport and assimilatory reduction of sulfate and 
TABLE 1 | Abbreviations and synonyms used in this article.

\begin{tabular}{|c|c|c|}
\hline & Abbreviations & Synonyms \\
\hline \multicolumn{3}{|l|}{ Compounds } \\
\hline 5,10-Methenyl-THF & $5,10=\mathrm{CH}-\mathrm{THF}$ & \\
\hline 5,10-Methylene-THF & $5,10-\mathrm{CH}_{2}-\mathrm{THF}$ & \\
\hline 5-Methyl-THF & $5-\mathrm{CH}_{3}-\mathrm{THF}$ & \\
\hline 10-Formyl-THF & 10-HCO-THF & \\
\hline 1-Aminocyclopropane 1-carboxylate & ACC & \\
\hline S-adenosylhomocysteine & AdoHcy & $\mathrm{SAH}$ \\
\hline S-adenosylmethionine & AdoMet & SAM \\
\hline Adenosine-5'-phosphate & APS & \\
\hline Cystathionine & CysT & \\
\hline Decarboxylated AdoMet & dAdoMet & dcSAM \\
\hline $\begin{array}{l}\text { 1,2-Dihydro-3-keto-5- } \\
\text { methylthiopentene }\end{array}$ & $\mathrm{DHKMP}$ & \\
\hline Homocysteine & Hcy & Hcys \\
\hline 5'-Methylthioadenosine & MTA & \\
\hline 2-Keto-4-methylthiobutyrate & KMTB & KMBA \\
\hline 5-Methylthioribose & MTR & \\
\hline 5-Methylthioribose-1-phosphate & MTR-P & MTR-1-P \\
\hline 5-Methylthioribulose-1-phosphate & MTRu-P & MTRu-1-P \\
\hline Nicotianamine & NA & \\
\hline$N$-acetylserine & NAS & \\
\hline O-acetylserine & OAS & \\
\hline O-phosphohomoserine & $\mathrm{OPH}$ & \\
\hline 3'-Phospho-APS & PAPS & \\
\hline 3-Phosphoglycerate & PGA & \\
\hline S-Methylmethionine & SMM & \\
\hline Tetrahydrofolate & THF & \\
\hline \multicolumn{3}{|l|}{ Enzymes } \\
\hline ACC oxidase & ACO & \\
\hline Arg decarboxylase & ADC & \\
\hline Adenosine kinase & ADK & \\
\hline AdoMet decarboxylase & AdoMetDC & SAMDC \\
\hline $\begin{array}{l}\text { Alanine:hydroxypyruvate (Ser:pyruvate) } \\
\text { aminotransferase }\end{array}$ & AH-AT & \\
\hline Aspartate kinase & AK & \\
\hline APS kinase & APK & \\
\hline APS reductase & APR & \\
\hline Acidoreductone oxygenase & ARD & \\
\hline ATP sulfurylase & ATPS & \\
\hline Cystathionine $\beta$-lyase & $\mathrm{CBL}$ & \\
\hline Cdystathionine $\gamma$-synthase & CGS & \\
\hline Cysteine synthase complex & CSC & \\
\hline $\begin{array}{l}\text { Dehydratase-enolase-phosphatase- } \\
\text { complex } 1\end{array}$ & DEP1 & \\
\hline Glycine decarboxylase complex & GDC & \\
\hline 10-Formyl-THF synthetase & FTHFS & \\
\hline Glycerate dehydrogenase & $\mathrm{GDH}$ & \\
\hline Glycerate kinase & GLYK & \\
\hline Homocysteine S-methyltransferase & HcySMT & \\
\hline Histone methyltransferase & HMT & \\
\hline Hydroxypyruvate reductase & HPR & \\
\hline Homoserine dehydrogenase & $\mathrm{HSDH}$ & \\
\hline
\end{tabular}

(Continued)
TABLE 1 | Continued

\begin{tabular}{|c|c|c|}
\hline & Abbreviations & Synonyms \\
\hline $\begin{array}{l}\text { S-adenosylmethionine } \\
\text { synthetase/methionine } \\
\text { adenosyltransferase }\end{array}$ & MAT & SAM synthase, SAMS \\
\hline Methionyl-tRNA synthetase & MetRS & \\
\hline Methionine S-methyltransferase & MetSMT & \\
\hline Methionine synthase & MS & \\
\hline 5,10-Methenyl-THF cyclohydrolase & MTHFC & \\
\hline 5,10-Methylene-THF dehydrogenase & MTHFD & \\
\hline Bifunctional MTHFD/MTHFC & MTHFD/C & \\
\hline 5,10-Methylene-THF reductase & MTHFR & \\
\hline $\begin{array}{l}\text { 5-Methylthioribose-1-phosphate } \\
\text { isomerase }\end{array}$ & MTI & \\
\hline 5-Methylthioribose kinase & MTK & \\
\hline 5-Methylthioadenosine nucleosidase & MTN & \\
\hline O-acetylserine-(thiol)-lyase & OAS-TL & OASS \\
\hline 3-Phosphoglycerate phosphatase & PGAP & \\
\hline 3-Phosphoglycerate dehydrogenase & $\mathrm{PGDH}$ & \\
\hline 3-Phosphoserine aminotransferase & PSAT & \\
\hline 3-Phosphoserine phosphatase & PSP & \\
\hline S-Adenosylhomocysteine hydrolase & $\mathrm{SAHH}$ & \\
\hline Serine acetyltransferase & SERAT & SAT \\
\hline Serine hydroxymethyltransferase & $\mathrm{SHM}$ & SHMT \\
\hline Sulfite reductase & SiR & \\
\hline Spermidine synthase & SPDS & \\
\hline Spermine synthase & SPMS & \\
\hline Threonine synthase & TS & \\
\hline Thermospermine synthase & TSPMS & \\
\hline
\end{tabular}

Cys biosynthesis from several operons belonging to a cys regulon regulated by a transcriptional regulator CysB (see section "OAS and $\mathrm{N}$-Acetylserine Regulate Transcription in Bacteria and Plants"). Generally, the cytosol is the major site for the assimilation and synthesis of Cys in bacteria. In plants, the sulfate reduction pathway, which produces sulfide, is mainly localized to plastids, whereas the syntheses of OAS and Cys are localized to multiple compartments, including the cytosol, plastids, and mitochondria (Saito, 2004; Takahashi et al., 2011) (Figure 1). The activity distributions of the dominant SERAT and OASTL differed between the subcellular compartments, tissues, and species. For Arabidopsis thaliana (hereafter Arabidopsis), there are five SERAT isoforms and three OAS-TL isoforms, which are distributed over the three compartments (Noji et al., 1998; Wirtz et al., 2001; Kawashima et al., 2005; Haas et al., 2008; Heeg et al., 2008; Watanabe et al., 2008a,b). In Arabidopsis leaf, mitochondrial SERAT and cytosolic OAS-TL predominantly contribute to the production of OAS and Cys, respectively, but the dominant contributions seem to differ in other tissues, such as the roots, flower, silique, and seeds, and in different growth conditions (Heeg et al., 2008; Watanabe et al., 2008a,b; Birke et al., 2013). In other species, dominant SERAT activity was detected in the cytosol of Citrullus vulgaris seedlings (Saito et al., 1995), in plastids of Spinacea oleracea leaf (Brunold and Suter, 1982), and 


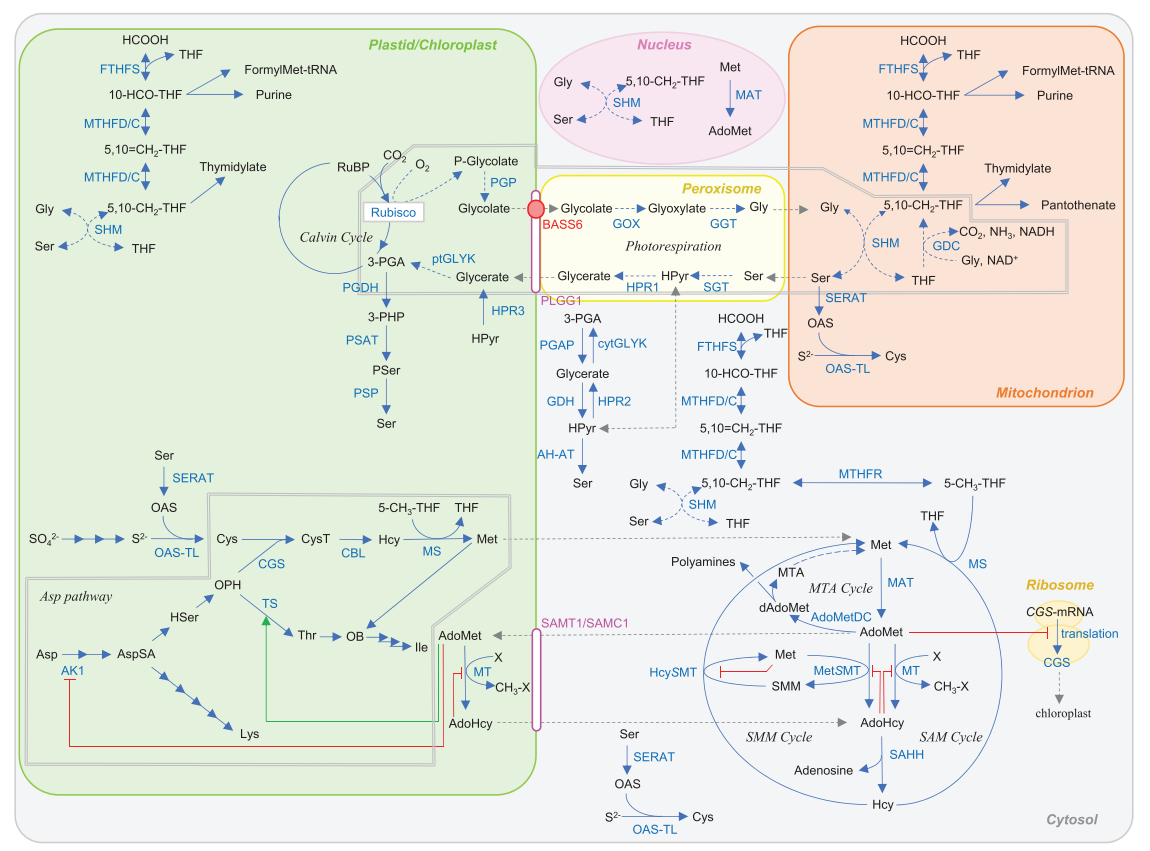

FIGURE 1 | Plant metabolic pathways targeted in this article. Red and green lines indicate repression and activation of the reaction by metabolites. Abbreviations: BASS6, bile acid sodium symporter 6; PLGG1, plastidal glycolate glycerate translocator 1; SAMT1/SAMC1, S-adenosylmethionine transporter 1/S-adenosylmethionine carrier 1. Other abbreviations are listed in Table 1.

in the mitochondria of Phaseolus vulgaris seedlings (Smith, 1972) and Pisum sativum leaves (Ruffet et al., 1995; Droux, 2003).

\section{Hcy Is Essential for de novo Met Synthesis and AdoMet Recycling}

Cys is further converted to another S-containing proteinogenic amino acid Met in plants and bacteria (Figure 1 for plants). This metabolic pathway comprised three reactions catalyzed by CysT $\gamma$-synthase (CGS), CysT $\beta$-lyase (CBL), and Met synthase (MS). CGS catalyzes the formation of CysT from Cys and $\mathrm{O}$-phosphohomoserine $(\mathrm{OPH})$, whereas $\mathrm{CBL}$ generates Hcy from CysT. In the last step of Met synthesis, the methyl group is transferred to an S atom of Hcy by MS using 5methyltetrahydrofolate (5- $\left.\mathrm{CH}_{3}-\mathrm{THF}\right)$ as a methyl donor. $\mathrm{OPH}$ provides a carbon skeleton of Met and works as the common biosynthetic precursor for threonine (Thr) and isoleucine (Ile). In plants, CGS and CBL are localized in the chloroplast, whereas MS is considered to exist in both the chloroplast and cytosol. Ravanel et al. (2004) reported that a chloroplastic MS isoform of Arabidopsis (AtMS3) was responsible for the methylation of Hcy that is synthesized de novo in this organelle, whereas two cytosolic MS isoforms (AtMS1 and AtMS2) are involved in the regeneration of Met from Hcy, which is derived from $S$-adenosylhomosysteine (AdoHcy), a product of methylation reactions that use AdoMet. The $5-\mathrm{CH}_{3}-\mathrm{THF}$ is synthesized by $5,10-\mathrm{CH}_{2}$-THF reductase (MTHFR) from methylene-THF $\left(5,10-\mathrm{CH}_{2}-\mathrm{THF}\right)$ and serves as a methyl donor in the reactions catalyzed by MS. However, as the plastids lack MTHFR and cannot generate $5-\mathrm{CH}_{3}-\mathrm{THF}$, it is not clear how they might make Met from Hcy (Christensen and MacKenzie, 2006). As AdoHcy inhibits methyltransferase activity (Tehlivets et al., 2013), degradation of AdoHcy by $S$-adenosylhomocysteine hydrolase (SAHH) into Hcy is important to maintain the activity of the methyltransferases involved in various important reactions. SAHH is localized only to the cytosol.

While bacteria have the same biosynthetic pathways for Met, animals cannot produce this amino acid and must acquire it from their diets. In animals, Cys is synthesized from Met via a pathway in which Met is sequentially converted to AdoMet, AdoHcy, Hcy, CysT, and finally Cys (Poloni et al., 2015).

In plant, Met is a member of the aspartate (Asp) family of amino acids because its carbon skeleton is derived from Asp. Among the nine essential amino acids for humans, lysine (Lys), Thr, Ile, and Met are synthesized from Asp in plants and bacteria. The biosynthetic pathway of these Asp-family amino acids (Asp pathway, surrounded by gray double line in Figure 1) in plants is finely regulated via feedback inhibition and stimulation of enzymatic activities by Lys, Thr, Ile, and AdoMet (Jander and Joshi, 2009; Galili et al., 2016). The pathway is also regulated at a translational level by AdoMet (see section "AdoMet Is a Critical Biomolecule Controlling Enzymatic Activity and Gene Expression at the Level of Transcription and Translation").

\section{AdoMet Provides Methyl and Aminopropyl Moieties and Is Recycled in the Three Cycles}

AdoMet is an important molecule that serves as a methyl donor in numerous methylation reactions in all living organisms. The 


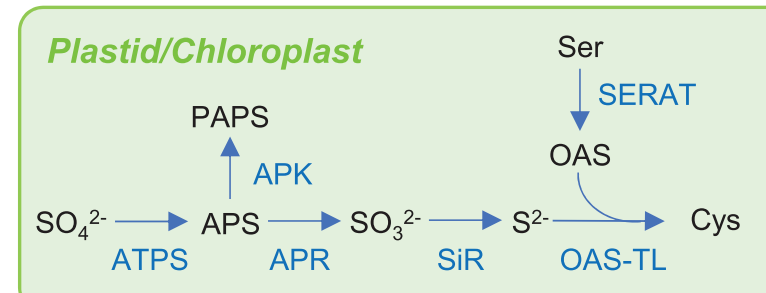

FIGURE 2 | Sulfur assimilation pathway in plant. Abbreviations are summarized in Table $\mathbf{1 .}$

methylation of DNA and histones regulates gene expression and thus various biological phenomena. Decarboxylated AdoMet (dAdoMet) serves as an aminopropyl donor for the synthesis of polyamines, which regulate growth and development in all living organisms (see section "AdoMet-Derived Polyamines and Ethylene Are Regulatory Metabolites in Stress Responses”). In plants, AdoMet is a precursor of the phytohormone ethylene and the iron chelator nicotianamine (NA) (Figure 3).

AdoMet is synthesized from Met and ATP by AdoMet synthetase (also known as Met adenosyltransferase and thus abbreviated as MAT). In mammals, MAT isoenzymes were classically considered to be cytosolic proteins (Pajares et al., 2013). However, they were also found in the nucleus, suggesting that they may function to provide AdoMet for the methylation of DNA and histones (Pajares et al., 2013). Similarly, AdoMet was previously considered to be synthesized only in the cytosol of plants (Ravanel et al., 2004). However, recent studies have shown that MAT isoenzymes are localized both in the nucleus and cytosol in Arabidopsis (Mao et al., 2015; Chen et al., 2016). Methylation reactions using AdoMet also occur in chloroplasts. AdoMet is imported from the cytosol to chloroplasts via SAM transporter 1 (SAMT1)/SAM career 1 (SAMC1), which is localized to the chloroplast envelope membranes and functions as an AdoMet-AdoHcy antiporter (Bouvier et al., 2006; Palmieri et al., 2006). As mentioned above, AdoHcy, a product of methylation reactions, needs to be transported to the cytosol and degraded by SAHH to form Hcy.

$\mathrm{Hcy}$ derived from AdoHcy degradation is regenerated into Met by MS in the cytosol of yeast, mammals, and plants (Figure 3). Consequently, the conversion of Met-AdoMetAdoHcy-Hcy-Met forms the SAM cycle in cytosol. In addition, plants have another Met recycling system from Hcy called the $S$-methylmethionine (SMM) cycle, which involves Met $S$-methyltransferase (MetSMT) and Hcy S-methyltransferase (HcySMT) in the cytosol. MetSMT and HcySMT catalyze the conversion of AdoMet to AdoHcy and Hcy to Met, respectively, coupled with the conversion between Met and SMM (Sauter et al., 2013). SMM is a storage form of $S$ and methyl groups in the leaves and a transport form of reduced $S$ in the phloem (Bourgis et al., 1999). The SMM cycle plays a role in the maintenance of the AdoMet/AdoHcy ratio (Kocsis et al., 2003), which is thought to be a metabolic indicator of the methylation potential (Hoffman et al., 1979; Moffatt and Weretilnyk, 2001).
In plants, AdoMet is utilized for the biosynthesis of polyamines, NA, and ethylene. In these biosynthetic reactions, $5^{\prime}$-methylthioadenosine (MTA) is generated as a common by-product. MTA is a product inhibitor of spermidine synthase (SPDS), spermine synthase (SPMS), thermospermine synthase (TSPMS), NA synthase, and ACC synthase (ACS) involved in ethylene biosynthesis, and its accumulation is toxic. Then, MTA is detoxified and recycled via the Met salvage cycle (also known as the Yang cycle or MTA cycle) in the cytosol to generate Met (Sauter et al., 2013) (Figure 3). This cycle is common in plants, mammals, and bacteria, but involved enzymes seem to have been recruited from different metabolic pathways, depending on organisms during evolution (Sekowska et al., 2019). Unexpectedly, transcriptome analyses suggested that the MTA cycle genes in plant are specifically expressed in phloem. This hypothesis on phloemspecific expression was confirmed experimentally and further resulted in identification of 5-methylthioribose-1-phosphate isomerase 1 (MTI1) and dehydratase-enolase-phosphatase complex 1 (DEP1), which had been missing enzymes in plant (Pommerrenig et al., 2011). DEP1 is responsible for the conversion of 5-methylthioribulose-1-phosphate (MTRu-P) to 1,2-dihydro-3-keto-5-methylthiopentene (DHKMP) in plant, whereas in Bacillus, the conversion is catalyzed by three enzymes. Interestingly, one of three enzymes, 2,3-diketo-5methylthiopentyl-1-phosphate enolase in a non-photosynthetic bacterium Bacillus, is an analog of ribulose bisphosphate carboxylase/oxygenase (RuBisCO) (Ashida et al., 2003).

\section{One-Carbon Metabolism Involves Tetrahydrofolate and AdoMet Metabolism}

One-carbon $\left(\mathrm{C}_{1}\right)$-substituted folates are required for the biosynthesis of various important molecules. The methyl moiety of AdoMet is also derived from $\mathrm{C}_{1}$-substituted folates, and thus, $\mathrm{C}_{1}$ metabolism is essential in all living organisms. $\mathrm{C}_{1}$ derivatives of tetrahydrofolate (THF) are interconverted between different oxidation states, ranging from the most oxidized 10-formyl(10-HCO-) THF through to 5,10-methenyl- $\left(5,10=\mathrm{CH}_{2}^{-}\right)$THF and 5,10-methylene- $\left(5,10-\mathrm{CH}_{2}-\right)$ THF to the most reduced 5methyl- (5- $\left.\mathrm{CH}_{3}-\right)$ THF (Hanson et al., 2000) (Figure 4). The $5,10-\mathrm{CH}_{2}$-THF is generated from the conversion of $5,10=\mathrm{CH}_{2}$ THF catalyzed by $5,10-\mathrm{CH}_{2}$-THF dehydrogenase (MTHFD). The $5,10-\mathrm{CH}_{2}$-THF is also synthesized via the reversible reaction of Ser and THF to form Gly and 5,10- $\mathrm{CH}_{2}-\mathrm{THF}$, which is catalyzed by Ser hydroxymethyltransferase (SHM). The conversion of $5,10=\mathrm{CH}_{2}$-THF to 10 -HCO-THF is catalyzed by $5,10=\mathrm{CH}-\mathrm{THF}$ cyclohydrolase (MTHFC). The 10-HCO-THF is used for the synthesis of purines and formylmethionyl-tRNA, which is used for translation initiation in plastids and mitochondria (Figure 1). The 5,10- $\mathrm{CH}_{2}$-THF is used for the synthesis of thymidylate and pantothenate. In eukaryotes, $C_{1}$ folate metabolism is found in multiple organelles, including the mitochondria and cytosol of mammals, whereas in plants, it is also found in plastids (Hanson et al., 2000; Christensen and MacKenzie, 2006). 


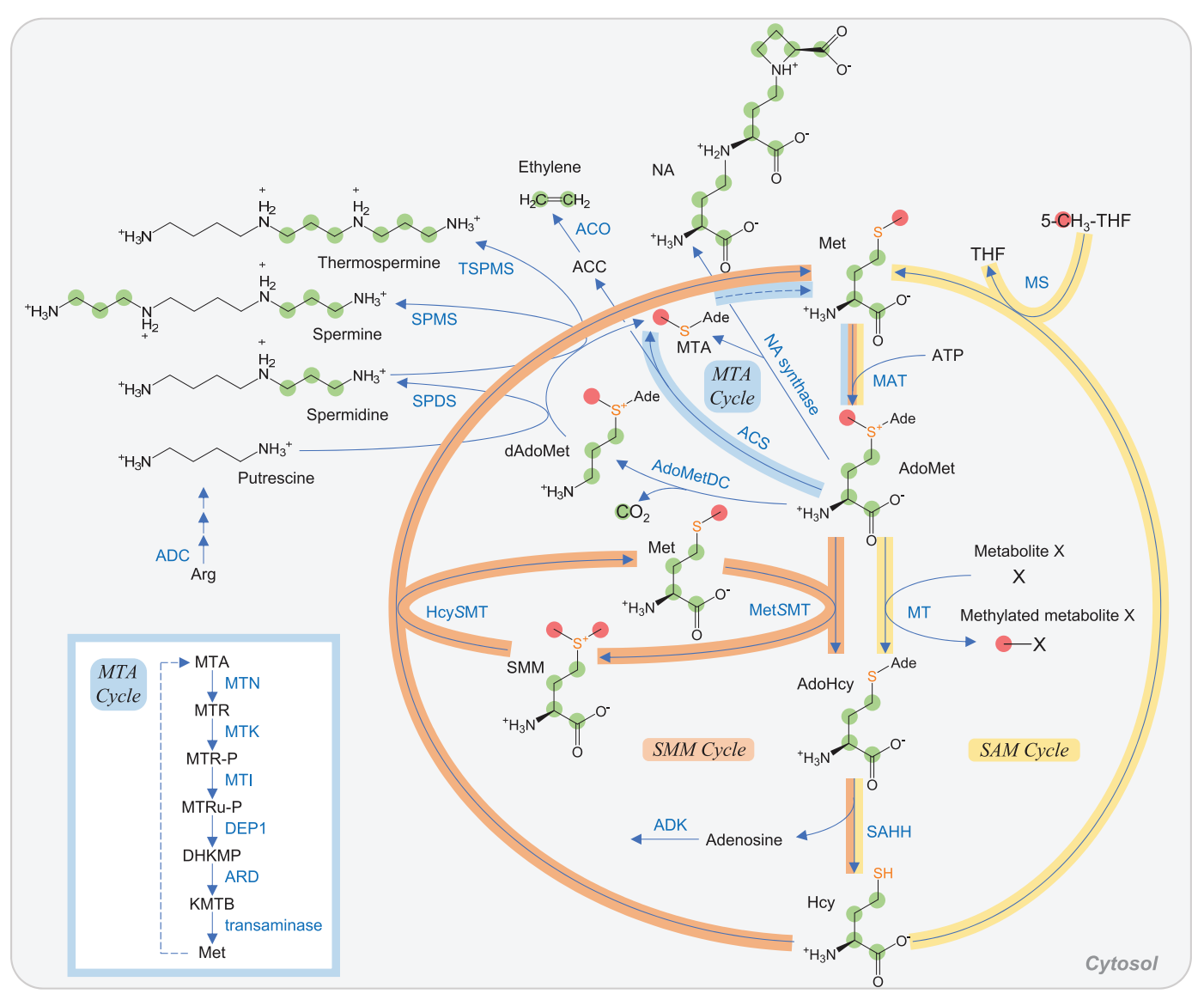

FIGURE 3 | AdoMet metabolism in plant. Carbon atoms of $\mathrm{C}_{1}$ unit and those derived from Asp are shown as red and green circles, respectively. Sulfur atoms derived from Cys are highlighted in orange. SAM cycle, SMM cycle, and MTA cycle (also known as the Yang cycle or Met salvage cycle) are indicated in yellow, orange, and pale blue, respectively. Among the reactions of the MTA cycle, six steps from MTA to Met are shown in the lower left box. Abbreviations: Ade, adenosyl group. Other abbreviations are listed in Table $\mathbf{1 .}$

However, MTHFR, which converts $5,10-\mathrm{CH}_{2}$-THF to 5-methyl(5- $\mathrm{CH}_{3}-$ )THF, is found only in the cytosol (Hanson et al., 2000; Christensen and MacKenzie, 2006) (Figure 4). In the cytosol, Met is regenerated from $\mathrm{Hcy}$ via MS using $5-\mathrm{CH}_{3}-\mathrm{THF}$ as a methyl donor in yeast, mammals, and plants (Christensen and MacKenzie, 2006). In Arabidopsis, a point mutation in the cytosolic bifunctional MTHFD/MTHFC (MTHFD1) resulted in the increase of THF $+5,10-\mathrm{CH}_{2}$-THF (these two compounds were not distinguished by the analysis) and the decrease of $5,10=\mathrm{CH}_{2}-\mathrm{THF}+10-\mathrm{HCO}-\mathrm{THF}$ (these two compounds were also not distinguished) (Groth et al., 2016). Moreover, the mutation caused the accumulation of AdoHcy and Hcy, DNA hypomethylation, and loss of histone H3 lysine 9 methylation, indicating the interconnection of THF metabolism, AdoMet recycling, and DNA methylation. One of the major differences among the organisms is that $\mathrm{C}_{1}$ metabolism in mitochondria is related to photorespiration in plants (Figure 1). In the mitochondria of both photosynthetic and non-photosynthetic plant tissues, the major $\mathrm{C}_{1}$ donor is Gly via mitochondrionspecific Gly decarboxylase complex (GDC). To satisfy the demands of photorespiration, the flux through GDC and SHM reactions is in the direction to make Ser from Gly. In contrast, in yeast, Ser is the major $\mathrm{C}_{1}$ donor in the mitochondria, and the SHM reaction is reversible (Christensen and MacKenzie, 2006).

SHM is a conserved enzyme in living organisms from bacteria to higher plants and mammals and plays an important role in $\mathrm{C}_{1}$ metabolism (McClung et al., 2000; Hanson and Roje, 2001; Bauwe and Kolukisaoglu, 2003). In plant, the SHM isoenzymes are localized in the cytosol, mitochondria, plastids, and nucleus (Ruszkowski et al., 2018). The SHM gene family consists of seven genes in Arabidopsis. The mitochondrial SHM1 and SHM2 are involved in the photorespiratory Gly-into-Ser conversion (Voll et al., 2006; Engel et al., 2007), and the plastidic SHM3 catalyzes a reversible hydroxymethyl group transfer from Ser to THF, yielding Gly and 5,10- $\mathrm{CH}_{2}-\mathrm{THF}$ (Zhang et al., 2010). SHM7 in the nucleus lacks conventional SHM activity and is required for AdoMet production (see section "OAS Cluster Genes: OAS Functions as a Signal in Plants").

Fluxes through the $\mathrm{C}_{1}$ pathways are particularly high in plants, because they are rich in methylated compounds such as lignin, alkaloids, and betaines (Hanson et al., 2000). 


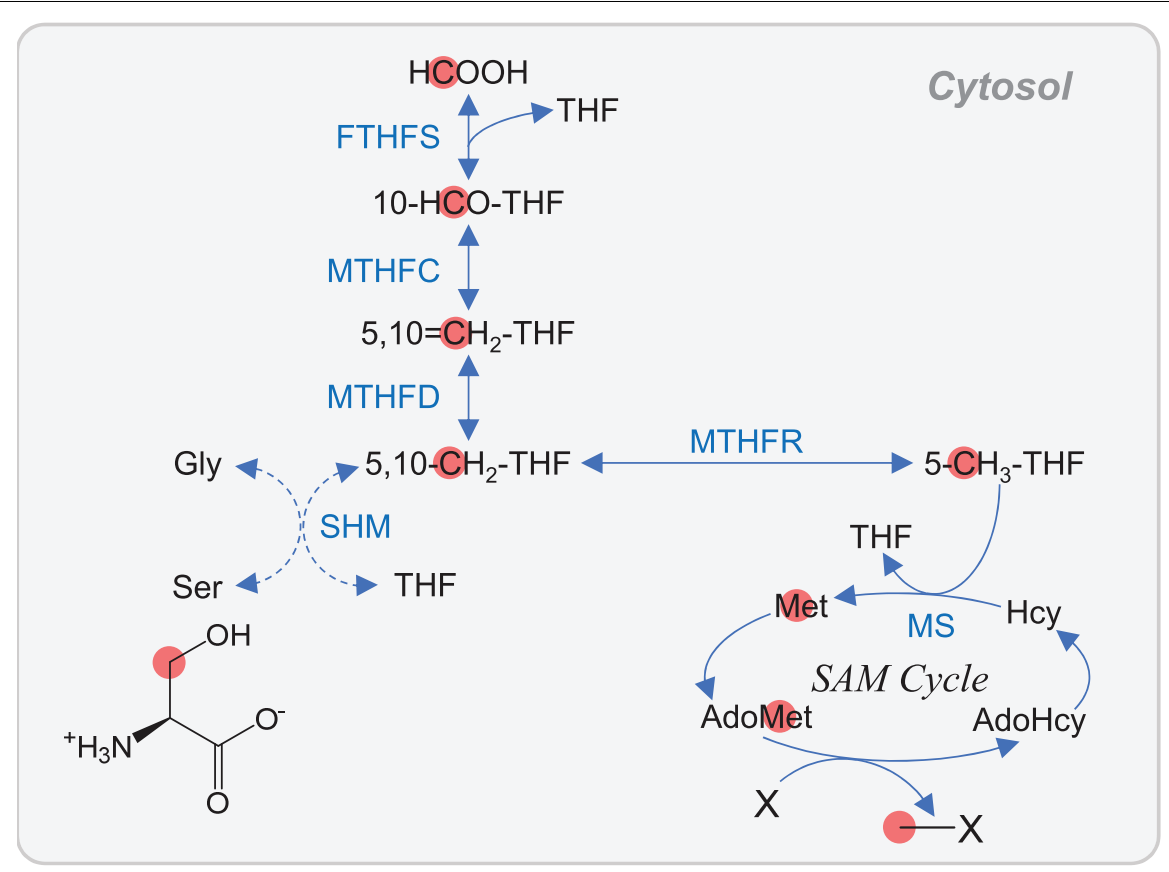

FIGURE $4 \mid \mathrm{C}_{1}$ metabolism in cytosol of plant. Carbon atoms of $\mathrm{C}_{1}$ unit are shown as red circles. Abbreviations are listed in Table 1. In Arabidopsis, the cytosolic bifunctional MTHFD/MTHFC is encoded by MTHFD1.

\section{Ser Metabolism Interconnects Metabolic Network}

The proteinogenic amino acid Ser has a function as a precursor for various essential biomolecules such as nucleic acid bases, phospholipids, sphingolipids, and other amino acids in all organisms. In mammal, Ser metabolism plays crucial roles in, for example, brain development and function, as well as endothelial cell proliferation (Hirabayashi and Furuya, 2008; Vandekeere et al., 2018; Le Douce et al., 2020). In plants, Ser plays important roles not only in development (see below) but also in the response to environmental stresses, such as high salinity, flooding, and low temperature (Ho and Saito, 2001).

In contrast to the Asp-family amino acids that human must acquire from their diet, Ser can be synthesized in all living organisms including humans. Plants have three Ser biosynthetic pathways in different organelles: the glycolate pathway in mitochondria, the phosphorylated pathway in chloroplasts, and the glycerate (non-phosphorylated) pathway in cytosol (Figure 5).

The glycolate pathway forms a part of photorespiration processes (Figures 1, 5) and is a major source of Ser in photosynthetic organs. In photorespiration, a toxic metabolite phosphoglycolate is formed via the oxygenase activity of RuBisCO in chloroplast. This metabolite is recycled to 3phosphoglycerate (PGA) in the sequential reactions occurring across chromoplast, peroxisome, and mitochondrion and turned back to the Calvin-Benson cycle. In the glycolate pathway, two Gly molecules are converted to one Ser molecule catalyzed by GDC and SHM in the mitochondria. Two transporters are involved in photorespiration processes: the plastidal glycolate glycerate translocator 1 (PLGG1) responsible for the simultaneous export of glycolate from and import of glycerate into the chloroplast (Pick et al., 2013) and the bile acid sodium symporter (BASS6) for export of glycolate from chloroplast (South et al., 2017).

The phosphorylated pathway of Ser biosynthesis, recently called PPSB, is common in plants, bacteria, and animals. In this pathway, PGA is converted to Ser via three-step reactions catalyzed by 3-PGA dehydrogenase (PGDH), 3-phosphoserine aminotransferase (PSAT), and 3-phosphoserine phosphatase (PSP) (Figure 5). In plants, these enzymes are localized in the plastid (Ho et al., 1998, 1999; Benstein et al., 2013; CascalesMiñana et al., 2013; Toujani et al., 2013a; Wulfert and Krueger, 2018). In Arabidopsis, PGDH, PSAT, and PSP are encoded by three genes, two genes, and one gene, respectively. Most of the genes are dominantly expressed in heterotrophic tissues, except AtPGDH3 and AtPSP1 (Benstein et al., 2013), suggesting that PPSB supplies Ser to the heterotrophic tissues. However, PPSB also plays a role in the photosynthetic organs when photorespiration is inhibited at night or under high $\mathrm{CO}_{2}$ conditions (Ros et al., 2014). In E. coli and Mycobacterium tuberculosis, PGDH is feedback-inhibited by Ser (Pizer, 1963: Dey et al., 2005), whereas PGDH of human and rat is not (Achouri et al., 1997; Dey et al., 2008). In Arabidopsis, AtPGDH1 and AtPGDH3, but not AtPGDH2, are inhibited by Ser (Benstein et al., 2013; Okamura and Hirai, 2017). In a basal land plant Marchantia polymorpha, a single gene-encoded MpPGDH is inhibited by Ser (Akashi et al., 2018). In addition, AtPGDH1, AtPGDH3, and MpPGDH are activated by alanine, valine, Met, homoserine, and Hcy, suggesting interaction between PPSB and 


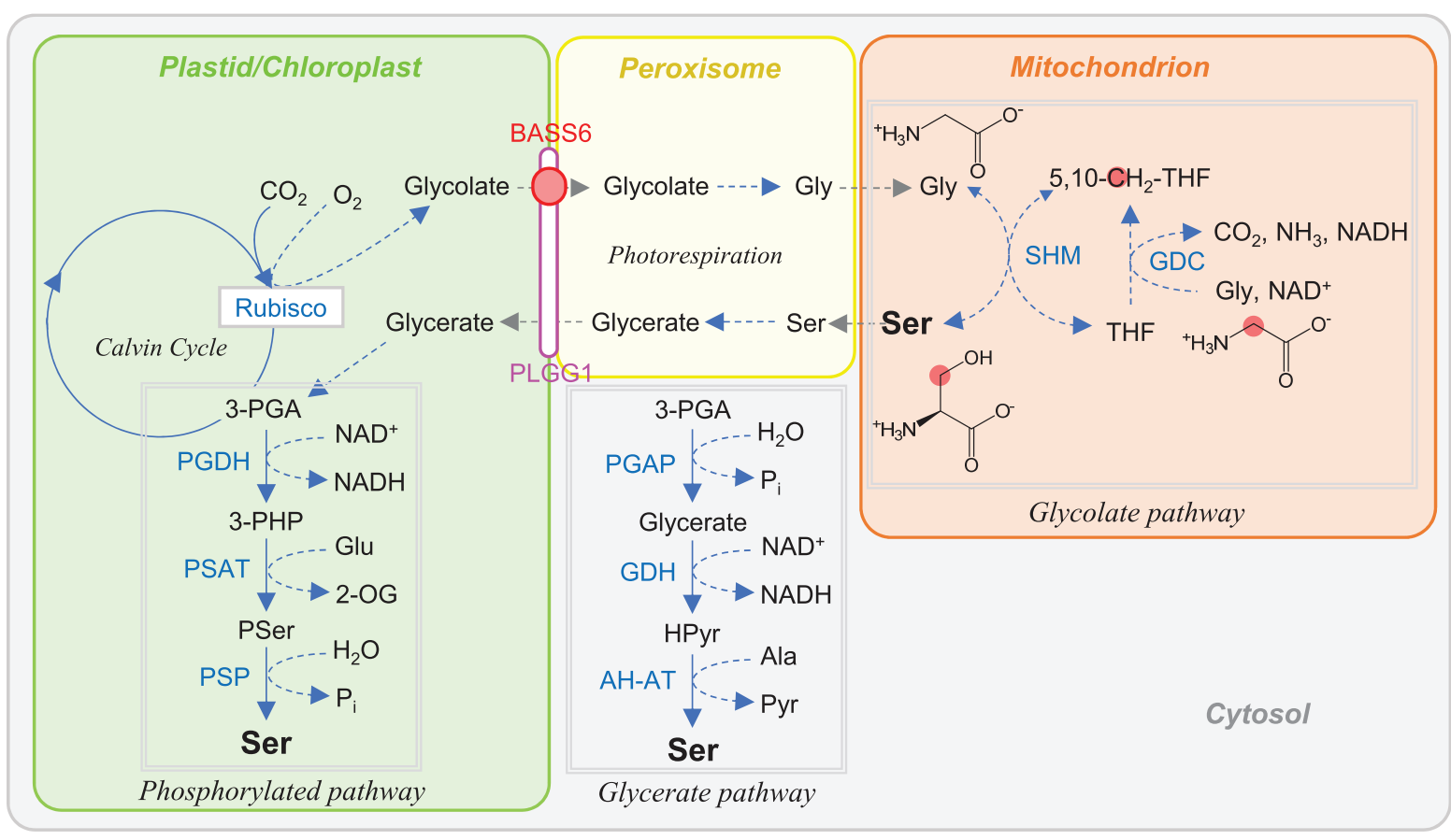

FIGURE 5 | Ser biosynthesis in plant. Carbon atoms of $C_{1}$ unit are shown as red circles. Abbreviations are listed in Table $\mathbf{1}$.

other amino acid metabolism (Okamura and Hirai, 2017; Akashi et al., 2018). AtPGDH1 and AtPSP1 are essential in pollen and embryo development (Benstein et al., 2013; Cascales-Miñana et al., 2013; Toujani et al., 2013b).

In the glycerate (non-phosphorylated) pathway, PGA is first dephosphorylated by PGA phosphatase and then subjected to the reactions catalyzed by glycerate dehydrogenase (GDH) and glycine:hydroxypyruvate (Ser:glyoxylate) and alanine:hydroxypyruvate (Ser:pyruvate) aminotransferases finally to form Ser (Igamberdiev and Kleczkowski, 2018). This pathway exists in the cytosol and is a major Ser source in the photosynthetic tissues of $\mathrm{C}_{4}$ plants, in darkness in $\mathrm{C}_{3}$ plants, and in non-photosynthetic tissues (Igamberdiev and Kleczkowski, 2018).

As mentioned in Section "OAS Is a Key Metabolite in Cys Synthesis," Ser is converted to OAS by SERAT and reacts with sulfide to form Cys. On the other hand, Ser reacts with indole and directly forms tryptophan (Trp) being catalyzed by Trp synthase. Thus, Ser provides a carbon skeleton to both Cys and Trp. Ser is also involved in $\mathrm{C}_{1}$ metabolism via SHM (see section "One-Carbon Metabolism Involves Tetrahydrofolate and AdoMet Metabolism”). In this way, Ser metabolism interconnects $\mathrm{S}$, Trp, and $\mathrm{C}_{1}$ metabolism.

\section{REGULATORY FUNCTION OF OAS, ADOMET, HCY, AND SER}

The aforementioned pathways are mutually regulated by fine mechanisms that utilize key metabolites as signaling molecules. In the following chapters, we introduce the regulatory mechanisms involving four amino acids, OAS, AdoMet, Hcy, and Ser.

\section{OAS}

Briefly, OAS has a signal function to regulate S-responsive gene expression. OAS also regulates Cys biosynthesis at enzymatic level.

\section{OAS and $\mathbf{N}$-Acetylserine Regulate Transcription in Bacteria and Plants}

OAS is considered a signal molecule in plants because it is highly accumulated in S-deficient conditions, and OAS and/or its isomer $N$-acetylserine (NAS) acts as a positive regulator for the biosynthesis of Cys and S utilization in bacteria (Ostrowski and Kredich, 1991; Lynch et al., 1994). In bacteria, the Cys regulon, consisting of more than 20 genes, is coordinately controlled by a LysR-type regulator CysB (Kredich, 1996; Van Der Ploeg et al., 2001; Parry and Clark, 2002). OAS and/or NAS bind to CysB, activating its binding to the promoter of genes in the Cys regulon and preventing autorepression (Kredich, 1996). Although several results from previous studies have suggested that OAS is spontaneously converted to NAS in a pH-dependent manner (Flavin and Slaughter, 1967) and that NAS is the true signal for the Cys regulon (Ostrowski and Kredich, 1989; Hryniewicz and Kredich, 1994; Lynch et al., 1994), recent research of ligand recognition by CysB in Salmonella typhimurium has proposed that CysB has two distinct ligand-binding sites: site1 for sulfate and NAS and site- 2 for NAS and OAS. The OAS remodels site- 1 by binding to site- 2 to enhance the NAS-mediated 
activation through allosteric coupling between sites (Mittal et al., 2017). Furthermore, N,O-diacetylserine produced from OAS in Salmonella enterica may be the true signal for the Cys regulon (Vandrisse and Escalante-Semerena, 2018). More studies are required to fully confirm the activation mechanisms of CysB.

In plants, some studies have demonstrated that OAS and not NAS induced the expression of enzymes for the sulfate assimilation pathway (Neuenschwander et al., 1991; Hawkesford et al., 1995), which is the reason why OAS is considered a signal molecule in plants. However, the mechanisms for the transcriptional activation of $S$ metabolism by OAS remain unclear in plants. Transcription regulators such as CysB or a receptor, which could be directory bound by OAS, have not yet been discovered.

\section{OAS Cluster Genes: OAS Functions as a Signal in Plants}

The role of OAS as a signal molecule in plants has been supported by the transcriptome analyses of sulfate starvation experiments (Hirai et al., 2003; Maruyama-Nakashita et al., 2003; Nikiforova et al., 2003), where OAS was accumulated in plants, and in OAS addition experiments (Koprivova et al., 2000; Kopriva et al., 2002; Hesse et al., 2003; Hopkins et al., 2005). The OAS concentration in Arabidopsis grown on full nutrient condition was approximately $1-10 \mathrm{nmol} / \mathrm{g}$ fresh weight in leaves and roots, whereas the concentration was increased by 10-100 times in S-starved plants (Maruyama-Nakashita et al., 2006; Hubberten et al., 2012a; Forieri et al., 2017). Hubberten et al. (2012b) succeeded in identifying OAS cluster genes (Table 2), which are specifically coexpressed with OAS accumulation, using metabolite-gene correlation analyses with time-series transcriptome and metabolome data in non-S-related experiments of Arabidopsis; the studies of natural diurnal oscillations (Espinoza et al., 2010) and responses to light and temperature (Caldana et al., 2011), where the OAS concentration was changed in the range from two to four times the baseline. Furthermore, they evaluated the OAS-correlated genes using inducible overexpression lines of SERAT (Hubberten et al., 2012b). The six OAS cluster genes were highly coexpressed in various experimental conditions in Arabidopsis (Obayashi et al., 2007, 2009; Mutwil et al., 2010) and in other plant species such as Oryza sativa and Populus trichocarpa (Mutwil et al., 2008; Mutwil et al., 2011). The promoter regions of the OAS cluster genes contained a conserved cis-element, UPE box (UP9 binding element; UPregulated by S deficit 9, see below), or UPE-like motif
(Wawrzynska et al., 2010). Transcription factors in the ethyleneinsensitive 3-like (EIL) family including S limitation 1 (SLIM1), which is a central transcriptional regulator of $\mathrm{S}$ responses in Arabidopsis (Maruyama-Nakashita et al., 2006), were reported to bind the UPE box (Wawrzynska et al., 2010).

Recent studies have shown that the OAS cluster genes are involved in S metabolism, although the function of APR3 has already been defined as a key-limiting enzyme in the assimilatory reduction of sulfate (Vauclare et al., 2002). The ChaC protein is considered to be a cation transporter because ChaC was identified as a gene of the Cha operon $\left(\mathrm{Ca}^{2+} / \mathrm{H}^{+}\right.$antiporter $)$ in E. coli (Ivey et al., 1993; Osborne et al., 2004). However, Kumar et al. (2012) found that mammalian ChaC has $\gamma$-glutamyl cyclotransferase (GGCT) activity degrading glutathione (GSH) to yield 5-oxoproline and cysteinyl-glycine for the recycling of GSH (Kumar et al., 2012). In the Arabidopsis genome, there are three ChaC genes, which all have GGCT activity (Kumar et al., 2015). Studies with knockout mutants or overexpression lines of the GGCT2;1, an OAS cluster gene, revealed that the GSH recycling by GGCT2;1 is important for heavy metal toxicity such as arsenite and cadmium (Paulose et al., 2013) and root system architecture during S starvation (Joshi et al., 2019).

The low sulfur-induced (LSU) gene was originally identified in Nicotiana tabacum as an S-responsive gene, named UP9 (Wawrzynska et al., 2005). UP9C, which is one of six UP9 genes, is highly upregulated under $\mathrm{S}$ starvation (Lewandowska et al., 2005) and has been suggested to be involved in the synthesis and signaling of ethylene (Moniuszko et al., 2013) and autophagy (Zientara-Rytter et al., 2011) through proteinprotein interactions. In the Arabidopsis genome, there are four $L S U$ genes, of which three (LSU1, 2LSU, and LSU3) are induced by S deficiency (Nikiforova et al., 2003, 2005a; Sirko et al., 2015), but only LSU1 was identified as an OAS cluster gene. In the largescale interactome studies of proteins, LSU proteins have been identified as network hubs coordinating abiotic stress responses (Garcia-Molina et al., 2017; Vandereyken et al., 2018). GarciaMolina et al. (2017) experimentally confirmed that LSU1 plays an important role in disease resistance to several abiotic stresses including nutrient deficiency, high salinity, or heavy metals via interactions with the chloroplastic Fe superoxide dismutase FSD2 (Garcia-Molina et al., 2017).

The sulfur deficiency-induced (SDI) gene was originally identified in wheat (Triticum aestivum var. Hereward) grown in S-deficient fields as an indicator of $S$ status by cDNAamplified fragment length polymorphism analysis (Howarth et al., 2005). In the Arabidopsis genome, there are five SDI

TABLE 2 | OAS cluster genes in Arabidopsis.

\begin{tabular}{|c|c|c|c|c|}
\hline Gene name & AGI code & Annotation & Function & References \\
\hline APR3 & At4g21990 & Adenosine-5'-phosphosulfate reductase 3 & Sulfur assimilation & Vauclare et al., 2002 \\
\hline ChaC/GGCT2;1 & At5g26220 & ChaC-like protein/ $\gamma$-glutamyl cyclotransferase & GSH degradation & Paulose et al., 2013; Joshi et al., 2019 \\
\hline LSU1 & At3g49580 & Low sulfur-induced 1 & & Garcia-Molina et al., 2017 \\
\hline SD/1 & At5g48850 & Sulfur deficiency-induced 1 & glucosinolate biosynthesis repressor & Aarabi et al., 2016 \\
\hline SDI2 & At1g04770 & Sulfur deficiency-induced 2 & glucosinolate biosynthesis repressor & Aarabi et al., 2016 \\
\hline SHM7/MSA1 & At1g36370 & Serine hydroxymethyltransferase $7 /$ more sulfur & 1 S-adenosylmethionine production & Huang et al., 2016 \\
\hline
\end{tabular}


genes categorized in the Male-sterile 5 (MS5) gene family, of which two SDI genes (SDI1 and SDI2) belong to the OAS cluster genes. Studies with knockout mutants or overexpression lines of the SDI genes revealed that SDI1 and SDI2 proteins acted as major repressors controlling glucosinolate biosynthesis in Arabidopsis (Aarabi et al., 2016). Further experiments using protein-protein interaction assays demonstrated that SDI1 physically interacts with MYB28, which is a positive regulator of aliphatic glucosinolates (Gigolashvili et al., 2007; Hirai et al., 2007; Sønderby et al., 2007; Malitsky et al., 2008), to repress the glucosinolate biosynthesis and use the sulfate preferentially for primary metabolites under S deficiency conditions (Aarabi et al., 2016, 2020).

The SHM7 gene was identified as the causal gene of the ethyl methanesulfonate-mutagenized more sulfur accumulation11 (msa1-1) mutant (Huang et al., 2016). Characterization of SHM7 and the msa1-1 mutant revealed that SHM7 lacks conventional SHM activity, is localized in the nucleus, and is required for AdoMet production and maintaining $\mathrm{S}$ homeostasis epigenetically via DNA methylation of, for example, the sulfate transporter genes SULTR1;1 and SULTR1;2 (Huang et al., 2016).

\section{OAS Regulates the Cys Synthase Complex}

SERAT (a dimer of homotrimers) and OAS-TL (a dimer) in the final steps of Cys biosynthesis form a hetero-oligomeric Cys synthase complex (CSC) (Kredich et al., 1969; Wang and Leyh, 2012). The CSC plays an important role in plant and bacterial $\mathrm{S}$ metabolism to strictly regulate the Cys concentrations in cells. The function for this CSC formation is not metabolic channeling. In the CSC, SERATs are activated or stabilized, whereas OAS-TLs are inactivated. OAS-TLs are fully active in the free form (Kredich et al., 1969; Droux et al., 1998; Mino et al., 2001). The balance of the complex and free forms of SERAT and OAS-TL is regulated by precursors of Cys synthesis, OAS and sulfide (Kredich et al., 1969; Droux et al., 1998; Mino et al., 2001). OAS dissociates the CSC, whereas sulfide is associated with CSC formation; hence, the association stimulates OAS formation, whereas the dissociation stimulates both OAS consumption and Cys formation. In addition to the regulation of CSC, SERAT activity is feedback inhibited by Cys (Kredich et al., 1969; Hindson, 2003; Olsen et al., 2004). The quaternary structures of the CSC from the bacteria and plants are highly similar, but the affinity of the CSC formation and the regulation of Cys sensitivity of SERAT within the CSC are different (Wirtz et al., 2010). For example, the affinity of CSC in Arabidopsis is 10 times weaker than that of bacterial CSCs in S. typhimurium, Haemophilus influenzae, and E. coli. The CSC formation decreases the sensitivity of SERAT to feedback inhibition by Cys in plants, whereas that of bacterial SERAT is not affected by the CSC formation. SERATs in bacteria such as E. coli (Kredich, 1996; Hindson, 2003; Olsen et al., 2004) and S. typhimurium (Kredich, 1996) are sensitive to feedback inhibition by Cys. The importance of CSC formation was well studied in Arabidopsis and soybean. Cytosolic and mitochondrial SERATs in Arabidopsis and cytosolic SERAT in soybean, which are feedback-sensitive by Cys, are less sensitive to the inhibition in CSC in vitro assay (Wirtz et al., 2010). Furthermore, the importance of CSC formation in vivo to regulate SERAT activity, and consequently, Cys production was proven by analyzing Arabidopsis T-DNA mutants of mitochondrial SERAT and OASTL (Wirtz et al., 2012). In plants, generally there are multiple SERAT isoforms localized in several subcellular compartments. The presence of Cys feedback regulation differs both between plant species and between subcellular compartments. For example, cytosolic SERAT isoforms in C. vulgaris (Saito et al., 1995) and Allium tuberosum (Urano et al., 2000) and plastidial isoforms in S. oleracea (Noji et al., 2001) and P. sativum (Droux, 2003) are sensitive to the feedback inhibition.

\section{Transporters of OAS Are Necessary for Signaling Function}

In bacteria, to act as signal molecules binding to a regulator $\mathrm{Cys} B$ in the nucleus, OAS and/or NAS, which are biosynthesized in the cytosol, need to be transported into the nucleus. Ions and small metabolites are expected to diffuse through water-filled channels in the nuclear pore complex (Beck and Hurt, 2017). In contrast to the bacteria, OAS, which is presumed to be a true signal in plants, is synthesized in multiple compartments, including the cytosol, plastids, and mitochondria (Saito, 2004; Takahashi et al., 2011). Several previous investigations using Arabidopsis knockout mutants of SERATs and OAS-TLs have implied that OAS and Cys are transported between cellular compartments (Heeg et al., 2008; Lopez-Martin et al., 2008; Watanabe et al., 2008a,b; Krueger et al., 2009). However, the transport system is currently unclear in plants, although several transporters of OAS and Cys such as YdeD, YfiK, Bcr, and TolC, which export both compounds from the cytosol to the outside of the cells, have been identified in bacteria (Dassler et al., 2000; Franke et al., 2003; Koronakis et al., 2004; Yamada et al., 2006). The subcellular distribution of OAS is a key issue. It is not yet clear in which compartment OAS acts as a signal molecule, how OAS induces the OAS cluster genes, or whether the distribution of OAS between the compartments is limited or not. The identification of the transport system will be helpful to elucidate the mechanisms of gene induction by OAS and to understand why OAS and Cys synthesis takes place in multiple compartments in plants.

\section{OAS-Related Metabolites Also Function as Signals in S Assimilation Pathway}

In addition to OAS, other OAS-related metabolites such as sulfide, Cys, and GSH, which are interconnected in S assimilation pathway, are also considered to be possible signal molecules (Kopriva, 2006; Rouached et al., 2008). Sulfide, Cys, and GSH, which are reduced forms of $S$, significantly decrease sulfate uptake and sulfate assimilation via changing the activity of enzymes and the transcript levels of genes (Brunold and Schmidt, 1976; Lappartient et al., 1999; Westerman et al., 2001; Vauclare et al., 2002). In S starvation conditions and feeding of each compound, the concentrations of these possible signal molecules were changed all together in plants, leading to disagreement regarding which metabolites were the true signals. Recent studies progressively revealed the specific function of each metabolite as a signal molecule. Sulfide has been proven to be involved in protein persulfidation causing changes in the protein functions (Aroca et al., 2018). Cys has been reported to stimulate the synthesis of 
hormone abscisic acid (ABA) via inducing the transcript level of 9-cis-epoxycarotenoid dioxygenase 3 (NCED3), which is the key rate-limiting enzyme for ABA production (Batool et al., 2018). Dong et al. (2017) showed that Arabidopsis senses the availability of OAS as the carbon/nitrogen precursor for Cys synthesis with the general control non-derepressible 2 (GCN2) kinase and the availability of sulfide as the $S$ precursor for Cys synthesis with the target of rapamycin by downregulation of glucose metabolism. The identification of distinct signal function of each metabolite could help to understand the whole framework of S starvation responses of plants.

\section{AdoMet}

The most important feature of regulatory function of AdoMet is that it could control epigenomic code via DNA/histone methylation in development and stress responses.

\section{AdoMet Is a Critical Biomolecule Controlling Enzymatic Activity and Gene Expression at the Level of Transcription and Translation}

AdoMet is recognized as an active form of Met and is one of the most important S-containing metabolites in plants. AdoMet is a key regulator of the Asp pathway, a major methyl donor for various methylation reactions, and a precursor of the polyamine, ethylene, and NA biosynthesis.

AdoMet is directly synthesized from Met and thus a critical biomolecule for regulation of the biosynthesis of Met and other amino acids in the Asp family. AdoMet acts as an allosteric effector for inhibition of Asp kinase and activation of Thr synthase (Azevedo et al., 1997; Mas-Droux et al., 2006) (Figure 1). While most of the key steps in the Asp pathway are regulated by allosteric enzymes, CGS, which catalyzes the first committed step of Met biosynthesis, is not one of them. CGS is functional in chloroplasts; however, AdoMet biosynthesis occurs in the cytosol. CGS is a chloroplast protein encoded by the nuclear CGS1 gene in Arabidopsis. Its expression is regulated via negative feedback by temporal translation elongation arrest, followed by mRNA degradation in response to AdoMet (Chiba et al., 1999, 2003; Onouchi et al., 2005) (at the bottom right of Figure 1). Arabidopsis mto1 mutants, which overaccumulate soluble Met, are defects in this posttranscriptional regulation. The mto1 mutations are found as single amino acid changes in the short stretch of the CGS1 nascent peptide, called the MTO1 region. The MTO1 region acting as a cis element is necessary and sufficient for the feedback regulation of CGS1. The temporal translation arrest occurs at the Ser-94 codon immediately downstream of the MTO1 region. During the translation arrest, the CGS1 nascent peptide including the MTO1 region forms a compact conformation inside the ribosomal exit tunnel. Furthermore, the compaction is associated with the conformation changes of the rRNA in the ribosomal exit tunnel, which might be involved in the translational arrest of the CGS1 gene in response to the AdoMet (Onoue et al., 2011). To maintain the homeostasis of the AdoMet produced in the cytosol, the translational feedback regulation of CGS1 in the cytosol is thought to be an appropriate system by which to achieve a prompt response to AdoMet.
AdoMet is a universal methyl group donor for various methylated metabolites. After the methyl group is transferred by methyltransferases to the accepted substrate, AdoHcy is produced and then rapidly hydrolyzed to Hcy and adenosine by SAHH, because AdoHcy is a strong inhibitor of all AdoMet-dependent methyltransferases. The AdoMet/AdoHcy ratio is thought to be a metabolic indicator of the methylation potential (Hoffman et al., 1979; Moffatt and Weretilnyk, 2001). DNA and histone proteins can be target for methylation. Their methylation status acts as an epigenetic code, which then influence the regulation of gene expression. In Arabidopsis, the steady-state levels of AdoMet and AdoHcy are reported to be $\sim 15$ and $\sim 0.5 \mathrm{pmol} / \mathrm{mg}$ fresh weight, respectively, in rosette leaves (Groth et al., 2016), and 3.34 and $0.14 \mathrm{pmol} / \mathrm{mg}$, respectively, in leaves (Rocha et al., 2005). The AdoMet/AdoHcy ratio varies according to conditions. For example, under S deficiency, AdoMet significantly decreased in seedlings, whereas AdoHcy remained unchanged, resulting in the decrease of the AdoMet/AdoHcy ratio (Nikiforova et al., 2005b). In another study, AdoMet in root significantly decreased, and DNA methylation pathway genes were downregulated under $S$ deficiency, whereas AdoHcy also decreased to a greater extent than AdoMet, thus resulting in the increase of the AdoMet/AdoHcy ratio (Forieri et al., 2017). The study suggested that AdoMet amount itself is also important for methylation status. The AdoMet/AdoHcy ratio was also changed under iron (Fe) deficiency: the values were approximately 60 (control), 130 (S deficiency), and 180 (Fe deficiency) (calculated using the data from Forieri et al., 2017).

AdoMet/AdoHcy ratio is also important in mammals. Histone methyltransferases (HMTs) are enzymes that catalyze the transfer of methyl groups to histone proteins. Alterations to AdoMet-related metabolism affect the histone methylation status, suggesting a possible link between the AdoMet/AdoHcy ratio and HMT activity. These metabolic changes also lead to widespread secondary effects on stress responses and developmental pathways, which make it difficult to determine whether these changes on histone methylation are caused by the direct sensing of the AdoMet/AdoHcy ratio in the cells (Shyh-Chang et al., 2013; Ulanovskaya et al., 2013; Shiraki et al., 2014). However, recent studies have shown the direct effects of the AdoMet/AdoHcy ratio on histone methylation levels by demonstrating the kinetics of histone methylation turnover in response to AdoMet and AdoHcy availability (Mentch et al., 2015). As most of the HMTs are involved in the methylation of specific target genes, the metabolic status of AdoMet is critical for these gene-specific regulations.

In bacteria, AdoMet is an important metabolite, not only as a methyl group donor but also as an effector of riboswitches for regulating intracellular Met and AdoMet concentrations. Three evolutionarily distinct classes of AdoMet-binding riboswitches, the SAM-I, SAM-II, and SAM-III superfamilies, have been identified, of which the SAM-I riboswitch is widespread and the best studied in bacteria (Batey, 2011). The SAM-I riboswitches have been identified in many transcripts encoding enzymes involved in sulfate assimilation and Cys/Met biosynthesis, which include AdoMet biosynthesis itself (Grundy and Henkin, 1998). AdoMet is synthesized from Met and ATP by MAT and 
is converted to AdoHcy after the methyltransferase reaction. AdoHcy is hydrolyzed to Hcy and adenosine by $\mathrm{SAHH}$, and then, Hcy is recycled back to Met by MS. SAM-I, SAM-II, and SAM-III riboswitches were identified in the MAT, and SAM-I and SAM-III were in MS (Batey, 2011). The negativefeedback regulation of these enzyme genes by the AdoMetbinding riboswitch could be required for the proper maintenance of the intracellular AdoMet level.

\section{AdoMet Metabolism and DNA/Histone Methylation Are Involved in Development and Stress Responses}

As described in Section "AdoMet Is a Critical Biomolecule Controlling Enzymatic Activity and Gene Expression at the Level of Transcription and Translation," the AdoMet concentration and the AdoMet/AdHcy ratio in cells are related to the proper methylation potential of DNA and histone to maintain normal development. The studies using Arabidopsis mutants indicated that the AdoMet and folate metabolism affects the genome-wide DNA methylation level. The leaky mutants of SAMS3/MAT4 and SAHH1 (responsible for AdoMet synthesis and AdoHcy hydrolysis, respectively) and MTHFD1 (involving interconversion of folates) exhibited the genome-wide DNA demethylation and the reduced AdoMet/AdoHcy ratio, although the causal relationship between DNA demethylation and the reduced AdoMet/AdoHcy ratio remained to be further examined (Goto et al., 2002; Rocha et al., 2005; Groth et al., 2016; Meng et al., 2018). The knockout mutants of SAMS3/MAT4, SAHH1, and MTHFD1 genes were lethal, indicating that these genes are essential (Rocha et al., 2005; Groth et al., 2016). Adenosine kinase $(\mathrm{ADK})$ catabolizes adenosine and thus enhances AdoHcy hydrolysis via SAHH (Figure 3; see section "Metabolism and a Putative Regulatory Role of Hcy"). In the ADK-deficient lines, AdoHcy increased by 12-43-fold, and the AdoMet/AdoHcy ratio was greatly reduced (AdoMet $17.39 \mu \mathrm{M}$ and AdoHcy $0.34 \mu \mathrm{M}$ in wild-type leaves) (Moffatt et al., 2002). The content of methyl-esterified pectin in seed mucilage was decreased with the reduced $\mathrm{ADK}$ activity. Considering morphological abnormality of the ADK-deficient lines, ADK plays an important function to AdoMet recycling and various methyltransferase reactions (Moffatt et al., 2002).

DNA methylation is involved in the various biotic and abiotic responses in plants. For instance, genome-wide DNA hypermethylation was observed in Arabidopsis roots in response to cyst nematode infection (Hewezi et al., 2017). Infection of bacterial pathogen also induced widespread differential DNA methylation in Arabidopsis leaves, which is negatively correlated with the expression of nearby transcripts (Dowen et al., 2012). In the case of abiotic stresses, early studies demonstrated abiotic stress-induced changes in DNA methylation patterns on genomewide or specific regions, which are associated with transcriptional regulation of stress-responsive genes in some cases (Xu et al., 2015; Yong-Villalobos et al., 2015; Zhang et al., 2016). Afterward, research interest shifted to the epigenetic memory for abiotic stress responses in plants (Kinoshita and Seki, 2014; Chang et al., 2020). These studies suggest the interplays between the AdoMet and folate metabolism and epigenetic regulation that are important for plant stress adaptation. Recently, Gonzalez and Vera (2019) demonstrated that folate metabolism is key in the epigenetic regulation for plant immune system by elegant approach combining chemical and reverse genetic strategies.

Nutritional stresses alter metabolism and gene expression. Among them, Fe deficiency greatly affects $S$ metabolism because $\mathrm{Fe}$ forms $\mathrm{Fe}-\mathrm{S}$ clusters involved in electron transfer chains in mitochondria and chloroplasts (Balk and Schaedler, 2014). NA is a chelator of metal cations including Fe ions and synthesized by trimerization of three molecules of AdoMet (Figure 3). NA plays an important role in the internal transport of $\mathrm{Fe}$, which is critical for proper reproductive development of plants (Takahashi et al., 2003). Fe deficiency resulted in increase of reduced S-containing metabolites including AdoMet, which might further result in higher accumulation of NA (Forieri et al., 2017). Also, a significant increase of the AdoMet/AdoHcy ratio under Fe deficiency might contribute to the large perturbation of transcription (Forieri et al., 2017).

\section{AdoMet-Derived Polyamines and Ethylene Are Regulatory Metabolites in Stress Responses}

AdoMet is also involved in stress responses through AdoMetderived metabolites, such as polyamines and ethylene.

Polyamines are polycationic compounds with strong binding abilities for negatively charged biomacromolecules, such as acidic proteins, membrane phospholipids, and nucleic acids. Predominant forms of the polyamines in plants are diamine putrescine, triamine spermidine, and tetraamine spermine (Figure 3). Biosynthetic pathways for polyamines have been extensively studied in Arabidopsis (Hanfrey et al., 2001). The initial step of polyamine biosynthesis is decarboxylation of arginine (Arg) by Arg decarboxylase (ADC), and then two additional successive steps produce putrescine. Spermidine and spermine are synthesized by sequential additions of aminopropyl groups to putrescine and spermidine by SPDS and SPMS, respectively. These aminopropyl moieties are derived from dAdoMet produced by AdoMet decarboxylase (AdoMetDC) (Figure 3). Thermospermine, a structural isomer of spermine, is also produced from spermidine and dAdoMet by TSPMS. Interestingly, polyamine levels are increased in response to various abiotic stresses, such as salinity, drought, low and high temperatures, and nutrient deficiencies, suggesting a protective role for polyamines against environmental stresses (Groppa and Benavides, 2007; Alcázar et al., 2010). These responses are mostly due to the induction of gene expressions of polyamine biosynthesis genes under stress conditions (Alcázar et al., 2006, 2010; Cuevas et al., 2008). Especially, spermidine and spermine levels rely on the supply of dAdoMet. Elevated levels of spermine produced by the overexpression of AdoMetDC or SPMS genes in Arabidopsis enhanced the tolerance to drought and salt stresses (Gonzalez et al., 2011), whereas the tspms/spms double mutant showed opposite phenotypes due to reduced levels of spermine (Yamaguchi et al., 2006, 2007). Furthermore, transcriptome analyses using AdoMetDC or SPMS overexpressing plants demonstrated the inductions of several genes encoding key components in the stress signaling cascades, as well as a key enzyme of ABA biosynthesis, NCDE3, with spermine overaccumulation (Marco et al., 2011). The involvement of 
AdoMet-dependent polyamine biosynthesis in stress responses has been revealed in many plant species other than Arabidopsis via genetic engineering. There are many examples showing that transgenic plants, such as rice, tobacco, and tomato, with the AdoMetDC gene from different species have acquired greater tolerances to various environmental stresses (Roy and $\mathrm{Wu}, 2002$; Waie and Rajam, 2003; Cheng et al., 2009).

Ethylene is an important phytohormone involved in multiple physiological and morphological responses, such as inhibition of cell growth, induction of fruit ripening and abscission, and adaptation to environmental stresses. Its biosynthesis pathway consists of a simple two-step reaction: AdoMet is converted to 1-aminocyclopropane-1-carboxylic acid (ACC) by ACS, and then ACC is converted to ethylene by ACC oxidase (Figure 3). Ethylene biosynthesis is accelerated in response to various biotic and abiotic stresses, such as pathogen infection, osmotic, salt, and drought stresses. Under salt stress, plants must control reactive oxygen species (ROS) level to survive. ROS act as a signal molecule to acquire the salt stress tolerance, whereas excess ROS accumulation damages cellular structure (Qi et al., 2018). Ethylene has a dual role to modulate salt stress response: one is promoting ROS production and signaling to activate $\mathrm{Na}^{+} / \mathrm{K}^{+}$transport (Jiang et al., 2013), and the other is inducing the expression of ROS scavengers through ethylene signaling pathway (Peng et al., 2014). Supply of AdoMet is crucial for ethylene biosynthesis. Induction of MAT genes in response to abiotic stresses has been reported in several species, such as barley, sugar beet, cucumber, and tomato (Sánchez-Aguayo et al., 2004; Ma et al., 2017; He et al., 2019). In the case of barley, HvSAMS3 protein accumulation in leaves was enhanced under combined drought and salt stresses. The hvsams3 knockdown mutants reduced tolerance to the combined stress, which was associated with decreased level of ethylene and polyamines. Moreover, exogenous application of ethylene to the mutants improved the tolerance, suggesting that ethylene level relying on HvSAMS3 is important for acquisition of the tolerance to combined stresses at least in part (Ahmed et al., 2020).

Overall, these studies indicate that AdoMet is an important precursor of polyamine and ethylene and leads to stress tolerance in plants.

\section{Hcy}

Hcy metabolism seems to be influenced by environmental stresses, although there are few reports on its steady-state level owing to technical difficulty of measurement. Hcy regulates PGDH activity in vitro and thus may control Ser biosynthesis in vivo.

\section{Metabolism and a Putative Regulatory Role of Hcy}

As mentioned in Section "Ser Metabolism Interconnects Metabolic Network," the enzymatic activity of AtPGDH1, AtPGDH3, and MpPGDH is activated by Hcy in vitro with the lowest $\mathrm{EC}_{50}$ values among the other activator amino acids $(23 \mu \mathrm{M}$ for AtPGDH1; $69 \mu \mathrm{M}$ for AtPGDH3; $20 \mu \mathrm{M}$ for MpPGDH) (Okamura and Hirai, 2017; Akashi et al., 2018). In Arabidopsis, the steady-state levels of Hcy are $<1 \mathrm{pmol} / \mathrm{mg}$ fresh weight in rosette leaves (Groth et al., 2016). In the hypocotyls of yellow lupine (Lupinus luteus) seedlings, the concentration of total Hcy (including disulfide-bound forms) was $4.3 \mu \mathrm{M}$ (Jakubowski and Guranowski, 2003). Under S deficiency, the relative abundance of Hcy in Arabidopsis seedling was not significantly changed (Nikiforova et al., 2005b). On the other hand, perturbation of folate metabolism affected Hcy level: a point mutation in MTHFD1 resulted in the increase of Hcy to $\sim 7 \mathrm{pmol} / \mathrm{mg}$ fresh weight in Arabidopsis rosette leaves (Groth et al., 2016).

In mammals, Hcy is generated by hydrolysis of AdoHcy. $\mathrm{Hcy}$ is then converted to Cys via the transsulfuration pathway catalyzed by CysT $\beta$-synthase and CysT $\gamma$-lyase, which is the reverse reaction of the de novo Hcy biosynthesis (catalyzed by CGS and CBL) in plants. Otherwise, Hcy is remethylated to form Met via MS (using $5-\mathrm{CH}_{3}-\mathrm{THF}$ as the methyl donor) or betaine-HcySMT (using betaine as the methyl donor). Hcy is considered toxic because its reduction power is stronger than that of Cys. Hcy is metabolized to Hcy-thiolactone by methionyl-tRNA synthetase (MetRS) in an error-editing reaction that prevents the translational incorporation of Hcy into proteins (Jakubowski, 2000; Jakubowski and Guranowski, 2003). Hcythiolactone synthesis is also found in bacteria and plants (see below). It is chemically reactive as its carbonyl group reacts with epsilon-amino group of Lys residues in proteins to form an amide bond (Hcy- $N$-protein), which leads to protein damage (Jakubowski, 2000; Jakubowski and Guranowski, 2003).

Overall, there is relatively little information available for Hcy in plants, and this is probably because it has been considered an intermediate of Met biosynthesis and a by-product of AdoMet metabolism. In contrast to its metabolism in animals, Hcy is the direct precursor of Met in plants and is synthesized in the chloroplast from Cys through the transsulfuration reactions catalyzed by CGS and CBL (see Asp pathway in Figure 1). $\mathrm{Hcy}$ is also generated from AdoHcy via SAHH reactions in the cytosolic AdoMet and SMM cycles (Figure 3). Because AdoHcy is generated as a by-product of various AdoMet-dependent methylation reactions and inhibits methyltransferase activities, it must be efficiently removed by SAHH. Arabidopsis possesses two SAHH isoforms, SAHH1 and SAHH2, and the null mutation of SAHH1 resulted in embryonic lethality (Rocha et al., 2005), indicating the importance of removal of AdoHcy. Biochemical analysis suggested that $\mathrm{SAHH}$ forms oligomeric protein complexes in phylogenetically divergent land plants and that light stress regulates protein complex formation and phosphorylation of SAHH, although the responses differed between Arabidopsis and Physcomitrium patens (Alegre et al., 2020).

SAHH also catalyzes the reverse reaction (i.e., AdoHcy synthesis), and the equilibrium is driven toward AdoHcy hydrolysis by the removal of the hydrolysis products, Hcy and adenosine (Guranowski and Pawełkiewicz, 1977; Pereira et al., 2007). Hcy is recycled in the SAM and SMM cycles (Figure 3), whereas adenosine is recycled predominantly by $\mathrm{ADK}$; thus, $\mathrm{SAHH}$ and ADK are coordinately regulated developmentally and responding to environmental stresses (Pereira et al., 2007). For example, SAHH activity was increased by elicitation of the phytoalexin response in alfalfa cell culture (Edwards, 1996). The transcript levels of $\mathrm{SAHH}$ and $\mathrm{ADK}$ increased with increased $\mathrm{NaCl}$ concentration in spinach, probably to meet 
increased demand of AdoMet for the synthesis of Gly betaine, a compatible osmolyte (Weretilnyk et al., 2001). The SAHH transcripts increased in response to a UV stimulus in parsley (Logemann et al., 2000).

Jakubowski and Guranowski (2003) reported that Hcythiolactone is synthesized in plants. In the hypocotyls of yellow lupine (L. luteus) seedlings, Hcy-thiolactone was detected at a concentration of $<0.6 \mu \mathrm{M}$. Treatment with the antifolate drug aminopterin, which inhibits the methylation of Hcy to Met, enhanced the accumulation of Hcy $(245 \mu \mathrm{M})$ and the synthesis of Hcy-thiolactone. The level of Hcy- $N$-protein was also increased after the aminopterin treatment. The Met supplement inhibited Hcy-thiolactone synthesis in yellow lupine seedlings, suggesting the involvement of MetRS. The E. coli cells expressing rice (O. sativa) MetRS were found to catalyze the conversion of Hcy to Hcy-thiolactone. The Hcy-thiolactone-hydrolyzing enzyme was purified from yellow lupine seed meal, suggesting Hcy-thiolactone metabolism in plant.

\section{Ser}

Ser metabolism has important functions in development, although it remains to be clarified whether a regulatory molecule is Ser itself or Ser-related metabolites. Ser metabolism is also involved in stress responses such as salt tolerance and photosynthetic performance.

\section{Ser Metabolism Affects S Metabolism}

As mentioned in Section "Ser Metabolism Interconnects Metabolic Network," Ser metabolism interconnects S, Trp, and $\mathrm{C}_{1}$ metabolism. In this section, we focus on the relationship between Ser biosynthesis and S metabolism, because Ser is the direct precursor of OAS production.

The OAS formation by SERAT is an interface between Ser as a nitrogen/carbon source and Cys metabolism as an S source. Therefore, the production of Ser affects that of OAS and then S metabolism. Although a variety of mutants in Ser biosynthesis have been reported and showed a complexity of metabolite changes independently of the Ser levels with growth phenotypes (Collakova et al., 2008; Benstein et al., 2013; Cascales-Miñana et al., 2013; Kuhn et al., 2013; Toujani et al., 2013a), a recent study by Anoman et al. (2019) revealed that deficient lines of the two genes in the phosphorylated pathway (AtPGDH1 and AtPSP1) perturbed S homeostasis by regulating not only its biosynthesis, but also the transport and allocation of the thiols between photosynthetic and non-photosynthetic tissues. Specifically, the OAS level increased in both aerial parts and roots of AtPSP1- and AtPGDH1-deficient lines compared to controls (up to 2.7- and 4.2-fold the wild-type level, in the aerial parts and roots of AtPSP1-deficent line). Interestingly, in the presence of Ser in the growing medium, the OAS levels reverted to normal values (Anoman et al., 2019). On the other hand, in the Arabidopsis photorespiratory "a bout de souffle" (bou-2) mutant, with reduced activity of the mitochondrial GDC multienzyme due to knockdown of mitochondrial BOU transporter protein, Ser was increased by fourfold (day) and 10-fold (night), whereas Cys was increased by fivefold (day) and threefold (night), compared to wild type (Samuilov et al., 2018).
The three Ser biosynthetic pathways are strictly regulated in terms of timing, tissue specificity, and transport of Ser between compartments, which results in some limitations to compensate for the loss of Ser in either compartment (Voll et al., 2006; Engel et al., 2011; Ros et al., 2014). In the case of Arabidopsis, the Ser concentration in the plants seems not to be affected by changes in the downstream products of S metabolism, such as OAS, Cys, GSH, or others (Watanabe et al., 2018). This might be caused by the bigger pool sizes of Ser compared to those of $\mathrm{S}$ metabolites or the tight regulation of Ser production by homeostatic mechanisms, including a feedback inhibition of, for example, AtPGDH1 activity by Ser and an activation by S-containing amino acids such as Cys, Hcy, and Met (Okamura and Hirai, 2017; Akashi et al., 2018). The $\mathrm{EC}_{50}$ values of AtPGDH1, AtPGDH3, and MpPGDH against Ser are 6.6, 1.3, and $1.5 \mathrm{mM}$, respectively. These values are likely within the biological range of Ser concentration in plastid, because Ser was present at $1.32 \mathrm{mM}$ in chloroplasts from pea leaves (Mills and Joy, 1980).

The expression of AtPGDH1 is positively regulated by MYB34 and MYB51, the transcription factors regulating the biosynthetic genes of Trp and Trp-derived indole glucosinolates (Benstein et al., 2013). In addition, Trp-derived metabolites such as indole acetic acid and indole glucosinolates were decreased in AtPGDH1-silenced plants, indicating that AtPGDH1 is involved in supplying the Ser used as the precursor of Trp biosynthesis (Benstein et al., 2013). The activation of AtPGDH1 activity by the $\mathrm{S}$-containing amino acids may have a role to balance $\mathrm{S}$ and Trp metabolism.

\section{Ser Metabolism Is Involved in Development and Environmental Adaptation}

Ser metabolism is involved in adaptive responses to various environmental stresses. Plants subjected to low temperature and elevated salinity accumulate Ser (Ho and Saito, 2001). In certain halophytes, Ser is a precursor of ethanolamine, which is further converted to a compatible solute Gly betaine. A recent study showed that Ser was increased by threefold in aerial part and by eightfold in root of Arabidopsis under salt stress (RosaTellez et al., 2020). In this case, the expression of AtPGDH1 and AtPGDH2 was induced, whereas that of AtPGDH3 was repressed (Rosa-Tellez et al., 2020). This result indicated the isoform-specific functions of PGDH, although their roles in Ser accumulation remain to be clarified. Similarly, in Beta vulgaris, $B v P G D H a$ was induced, whereas $B v P G D H b$ was repressed under salt stress (Kito et al., 2017).

In Arabidopsis, each isoform of the phosphorylated pathway enzymes seems to have its specific function in development and stress responses. Among AtPGDHs, only the knockout of AtPGDH1, which was previously identified as the embryo sac development arrest 9 (EDA9) gene, results in embryonic lethality (Benstein et al., 2013; Toujani et al., 2013a). AtPGDH1 and $A t P G D H 2$ are regulated by MYB51, whereas AtPGDH3 is not (Benstein et al., 2013). Similarly, AtPSAT1, but not AtPSAT2, is regulated by MYB51 (Benstein et al., 2013). Also, the expressions of AtPGDH1, AtPGDH2, and AtPSAT1 are induced by infection of Botrytis (Benstein et al., 2013).

Because Ser biosynthesis involves NADH production (Figure 5), it is likely to affect $\mathrm{NAD}(\mathrm{P})^{+} / \mathrm{NAD}(\mathrm{P}) \mathrm{H}$ homeostasis 
and redox status of cell. In chloroplast, the reducing power is generated by photochemical reactions in the thylakoid membrane upon illumination. The redox cascade involving ferredoxin and thioredoxin ensures light-responsive coordination of chloroplast functions (Yoshida et al., 2020). AtPGDH1 is the target of redox regulation of chloroplast proteins, and this regulation is associated with the redox-active Cys pair uniquely found in land plant PGDH (Yoshida et al., 2020). Recently, Höhner et al. (2021) reported that AtPGDH3 plays a crucial role in NADH supply in plastid stroma and eventually in photosynthetic performance under natural fluctuating light environment.

The phosphorylated pathway plays a role in Ser supply in the photosynthetic organs when photorespiration is inhibited at night or under high $\mathrm{CO}_{2}$ conditions (Ros et al., 2014). Among three AtPGDHs, only AtPGDH1 expression was induced under high $\mathrm{CO}_{2}$ conditions (Benstein et al., 2013).

In all above cases, the regulation of $\mathrm{PGDH}$ at the transcriptional or enzymatic levels is in an isoform-specific manner. Because the basal land plant $M$. polymorpha has a single PGDH, land plants may have evolved various types of PGDH after gene duplication during evolution to cope with various environmental stresses.

\section{SUMMARY AND FUTURE PERSPECTIVES}

In this review, we summarized the metabolism of S-containing amino acids and related compounds and the $\mathrm{C}_{1}$ metabolism in plants, focusing on regulatory function of AdoMet, OAS, Hcy, and Ser, in comparison with those in bacteria and animals. The following are some aspects that should be addressed in the future, although some of them have been topics of discussion for a long time.

- It remains unclear why some enzymes exist redundantly in several compartments (e.g., SERAT and OAS-TL in the plastids, mitochondria, and cytosol). On the contrary, some enzymes are localized exclusively to specific compartments. For example, SAHH, which hydrolyzes AdoHcy, exists only in the cytosol, although AdoHcy is generated as a by-product by methyltransferase reactions in the cytosol, plastids, and nuclei, and inhibits methyltransferase activities.

- The above issue might be related to our insufficient understanding of enzyme localizations. Alternative splicing or alternative promoter usage may regulate subcellular localization of enzymes. For example, glycerate kinase, which is an essential enzyme for photorespiration and targeted to the chloroplast, is localized to the cytosol under shaded condition by phytochromemediated alternative promoter selection. It is a part of cytosolic photorespiratory bypass that alleviates fluctuating light-induced photoinhibition (Ushijima et al., 2017). The regulation of protein subcellular localization, which might be realized by translational regulation, is the issue we should tackle.

- Although several metabolic pathways function across organelles, not many transporters involved in the intercompartmental transport of metabolites have been identified. Considering previous efforts to find transporters, novel strategies for their identification are necessary. Bioinformatics and deep learning approaches may enable us to predict candidate genes. Transport mechanism of metabolites could be clarified by uptake experiments using isolated organelle, as is the case with Lee et al. (2014), where careful inspection of Cys uptake kinetics indicated the existence of multiple specific Cys transporters in the mitochondrial membranes. Such an approach is useful to identify transporters.

- The concentration of metabolites in each compartment is key for the regulation of metabolism. However, their measurements are difficult, because metabolites are rapidly converted to other metabolites by enzymatic and non-enzymatic reactions during the isolation of organelles for metabolite analyses. Metabolomics technology for subcellular-level analysis is required. Nonaqueous fractionation is a powerful technique to study the subcellular compartmentation of metabolites in three main cellular compartments, cytosol, plastids, and vacuoles. Krueger et al. (2009) clarified the distribution of S containing metabolites including sulfate, sulfide, OAS, Cys, $\gamma$-glutamyl Cys, and GSH in Arabidopsis using this method. Immunogold labeling method is also useful to study the metabolite distribution. Koffler et al. (2011) clarified the distribution of GSH precursors including Cys, $\gamma$-glutamyl Cys, glutamate, Gly in cytosol, plastids, mitochondria, nuclei, peroxisomes, and vacuoles in Arabidopsis.

- Furthermore, it must be considered that the metabolites may be non-uniformly present in the cell due to the generation of so-called membraneless organelles by phase separation. This is related to the concept of metabolon, in which metabolites are directly transferred from an enzyme to others in the sequential enzymatic reactions. In addition to the research to investigate protein condensates, live imaging of metabolites may help understand this issue.

It has long been known that amino acids regulate the activities of their biosynthetic enzymes in a feedback manner. As shown in this review, amino acids also regulate metabolism at translational and transcriptional levels, reflecting the status of internal and external environments. A recent study demonstrated that perturbation in Arg level results in stunted gametophore morphology in P. patens (Kawade et al., 2020). Arg itself or a related metabolite might be the metabolite, which directly regulates development.

In conclusion, with rapid advances in experimental technology, new regulatory mechanisms of metabolism and development will be discovered in which metabolites involved in amino acid metabolism act as signal molecules.

\section{AUTHOR CONTRIBUTIONS}

MW, YC, and MYH wrote the manuscript. All authors contributed to the article and approved the submitted version.

\section{FUNDING}

This study was supported by JSPS KAKENHI grant Nos. 19K06723 to MW and 20H04852 to MYH. 


\section{REFERENCES}

Aarabi, F., Kusajima, M., Tohge, T., Konishi, T., Gigolashvili, T., Takamune, M., et al. (2016). Sulfur deficiency-induced repressor proteins optimize glucosinolate biosynthesis in plants. Sci. Adv. 2:e1601087. doi: 10.1126/sciadv. 1601087

Aarabi, F., Naake, T., Fernie, A. R., and Hoefgen, R. (2020). Coordinating sulfur pools under sulfate deprivation. Trends Plant Sci. 25, 1227-1239. doi: 10.1016/ j.tplants.2020.07.007

Achouri, Y., Rider, M. H., Schaftingen, E. V., and Robbi, M. (1997). Cloning, sequencing and expression of rat liver 3-phosphoglycerate dehydrogenase. Biochem. J. 323(Pt 2), 365-370. doi: 10.1042/bj3230365

Ahmed, I. M., Nadira, U. A., Qiu, C. W., Cao, F., Chen, Z. H., Vincze, E., et al. (2020). The barley $S$-adenosylmethionine synthetase 3 gene HvSAMS3 positively regulates the tolerance to combined drought and salinity stress in Tibetan wild barley. Cells 9:1530. doi: 10.3390/cells9061530

Akashi, H., Okamura, E., Nishihama, R., Kohchi, T., and Hirai, M. Y. (2018). Identification and biochemical characterization of the serine biosynthetic enzyme 3-phosphoglycerate dehydrogenase in Marchantia polymorpha. Front. Plant Sci. 9:956. doi: 10.3389/fpls.2018.00956

Alcázar, R., Altabella, T., Marco, F., Bortolotti, C., Reymond, M., Koncz, C., et al. (2010). Polyamines: molecules with regulatory functions in plant abiotic stress tolerance. Planta 231, 1237-1249. doi: 10.1007/s00425-010-1130-0

Alcázar, R., Marco, F., Cuevas, J. C., Patron, M., Ferrando, A., Carrasco, P., et al. (2006). Involvement of polyamines in plant response to abiotic stress. Biotech. Lett 23, 1867-1876. doi: 10.1007/s10529-006-9179-3

Alegre, S., Pascual, J., Trotta, A., Angeleri, M., Rahikainen, M., Brosche, M., et al. (2020). Evolutionary conservation and post-translational control of S-adenosylL-homocysteine hydrolase in land plants. PLoS One 15:e0227466. doi: 10.1371/ journal.pone.0227466

Anoman, A. D., Flores-Tornero, M., Benstein, R. M., Blau, S., Rosa-Téllez, S., Bräutigam, A., et al. (2019). Deficiency in the phosphorylated pathway of serine biosynthesis perturbs sulfur assimilation. Plant Physiol. 180, 153-170. doi: 10.1104/pp.18.01549

Aroca, A., Gotor, C., and Romero, L. C. (2018). Hydrogen sulfide signaling in plants: emerging roles of protein persulfidation. Front. Plant Sci. 9:1369.

Ashida, H., Saito, Y., Kojima, C., Kobayashi, K., Ogasawara, N., and Yokota, A. (2003). A functional link between RuBisCO-like protein of Bacillus and photosynthetic RuBisCO. Science 10, 286-290. doi: 10.1126/science.1086997

Azevedo, R. A., Arruda, P., Turner, W. L., and Lea, P. J. (1997). The biosynthesis and metabolism of the aspartate derived amino acids in higher plants. Phytochemistry 46, 395-419. doi: 10.1016/s0031-9422(97)00319-1

Balk, J., and Schaedler, T. A. (2014). Iron cofactor assembly in plants. Annu. Rev. Plant Biol. 65, 125-153. doi: 10.1146/annurev-arplant-050213-035759

Batey, R. T. (2011). Recognition of S-adenosylmethionine by riboswitches. Wiley Interdiscip. Rev. RNA 2, 299-311. doi: 10.1002/wrna.63

Batool, S., Uslu, V. V., Rajab, H., Ahmad, N., Waadt, R., Geiger, D., et al. (2018). Sulfate is incorporated into cysteine to trigger ABA production and stomatal closure. Plant Cell. 30, 2973-2987. doi: 10.1105/tpc.18.00612

Bauwe, H., and Kolukisaoglu, U. (2003). Genetic manipulation of glycine decarboxylation. J. Exper. Bot. 54, 1523-1535. doi: 10.1093/jxb/erg171

Beck, M., and Hurt, E. (2017). The nuclear pore complex: understanding its function through structural insight. Nat. Rev. Mol. Cell Biol. 18, 73-89. doi: 10.1038/nrm.2016.147

Benstein, R. B., Ludewig, K., Wulfert, S., Wittek, S., Gigolashvili, T., Frerigmann, H., et al. (2013). Arabidopsis phosphoglycerate dehydrogenasel of the phosphoserine pathway is essential for development and required for ammonium assimilation and tryptophan biosynthesis. Plant Cell. 25, 50115029. doi: 10.1105/tpc.113.118992

Bick, J. A., Dennis, J. J., Zylstra, G. J., Nowack, J., and Leustek, T. (2000). Identification of a new class of $5^{\prime}$-adenylylsulfate (APS) reductases from sulfateassimilating bacteria. J. Bacteriol. 182, 135-142. doi: 10.1128/jb.182.1.135-142. 2000

Birke, H., Heeg, C., Wirtz, M., and Hell, R. (2013). Successful fertilization requires the presence of at least one major O-acetylserine(thiol)lyase for cysteine synthesis in pollen of Arabidopsis. Plant Physiol. 163, 959-972. doi: 10.1104/ pp. 113.221200
Bourgis, F., Roje, S., Nuccio, M. L., Fisher, D. B., Tarczynski, M. C., Li, C., et al. (1999). S-methylmethionine plays a major role in phloem sulfur transport and is synthesized by a novel type of methyltransferase. Plant Cell 11, 1485-1498. doi: $10.2307 / 3870977$

Bouvier, F., Linka, N., Isner, J.-C., Mutterer, J., Weber, A. P., and Camara, B. (2006). Arabidopsis SAMT1 defines a plastid transporter regulating plastid biogenesis and plant development. Plant Cell 18, 3088-3105. doi: 10.1105/tpc.105.040741

Brosnan, J. T., and Brosnan, M. E. (2006). The sulfur-containing amino acids: an overview. J. Nutri. 136, 1636S-1640S.

Brunold, C., and Schmidt, A. (1976). Regulation of adenosine- $5^{\prime}$-phosphosulfate sulfotransferase activity by H2S in Lemna minor L. Planta. 133, 85-88. doi: 10.1007/bf00386010

Brunold, C., and Suter, M. (1982). Intracellular localization of serine acetyltransferase in spinach leaves. Planta 155, 321-327. doi: 10.1007/ bf00429459

Caldana, C., Degenkolbe, T., Cuadros-Inostroza, A., Klie, S., Sulpice, R., Leisse, A., et al. (2011). High-density kinetic analysis of the metabolomic and transcriptomic response of Arabidopsis to eight environmental conditions. Plant J. 67, 869-884. doi: 10.1111/j.1365-313x.2011.04640.x

Cascales-Miñana, B., Munoz-Bertomeu, J., Flores-Tornero, M., Anoman, A. D., Pertusa, J., Alaiz, M., et al. (2013). The phosphorylated pathway of serine biosynthesis is essential both for male gametophyte and embryo development and for root growth in Arabidopsis. Plant Cell 25, 2084-2101. doi: 10.1105/tpc. 113.112359

Chang, Y. N., Zhu, C., Jiang, J., Zhang, H., Zhu, J. K., and Duan, C. G. (2020). Epigenetic regulation in plant abiotic stress responses. J. Integr. Plant Biol. 62, 563-580. doi: 10.1111/jipb.12901

Chen, Y., Zou, T., and McCormick, S. (2016). S-adenosylmethionine synthetase 3 is important for pollen tube growth. Plant Phys. 172, 244-253. doi: 10.1104/pp. 16.00774

Cheng, L., Zou, Y., Ding, S., Zhang, J., Yu, X., Cao, J., et al. (2009). Polyamine accumulation in transgenic tomato enhances the tolerance to high temperature stress. J. Integr. Plant Biol. 51, 489-499. doi: 10.1111/j.1744-7909.2009. 00816.x

Cherest, H., and Surdin-Kerjan, Y. (1992). Genetic analysis of a new mutation conferring cysteine auxotrophy in Saccharomyces cerevisiae: updating of the sulfur metabolism pathway. Genetics 130, 51-58. doi: 10.1093/genetics/130.1.51

Chiba, Y., Ishikawa, M., Kijima, F., Tyson, R. H., Kim, J., Yamamoto, A., et al. (1999). Evidence for autoregulation of cystathionine $\gamma$-synthase mRNA stability in Arabidopsis. Science 286, 1371-1374. doi: 10.1126/science.286.5443.1371

Chiba, Y., Sakurai, R., Yoshino, M., Ominato, K., Ishikawa, M., Onouchi, H., et al. (2003). S-adenosyl-L-methionine is an effector in the posttranscriptional autoregulation of the cystathionine $\gamma$-synthase gene in Arabidopsis. Proc. Natl. Acad. Sci. U.S.A. 100, 10225-10230. doi: 10.1073/pnas.1831512100

Christensen, K. E., and MacKenzie, R. E. (2006). Mitochondrial one-carbon metabolism is adapted to the specific needs of yeast, plants and mammals. Bioessays 28, 595-605. doi: 10.1002/bies.20420

Collakova, E., Goyer, A., Naponelli, V., Krassovskaya, I., Gregory, J. F., Hanson, A. D., et al. (2008). Arabidopsis 10-formyl tetrahydrofolate deformylases are essential for photorespiration. Plant Cell 20, 1818-1832. doi: 10.1105/tpc.108. 058701

Cuevas, J. C., López-Cobollo, R., Alcázar, R., Zarza, X., Koncz, C., Altabella, T., et al. (2008). Putrescine is involved in Arabidopsis freezing tolerance and cold acclimation by regulating abscisic acid levels in response to low temperature. Plant Physiol. 148, 1094-1105. doi: 10.1104/pp.108.122945

Dassler, T., Maier, T., Winterhalter, C., and Bock, A. (2000). Identification of a major facilitator protein from Escherichia coli involved in efflux of metabolites of the cysteine pathway. Mol. Microbiol. 36, 1101-1112. doi: 10.1046/j.13652958.2000.01924.x

Dey, S., Burton, R. L., Grant, G. A., and Sacchettini, J. C. (2008). Structural analysis of substrate and effector binding in Mycobacterium tuberculosis D-3phosphoglycerate dehydrogenase. Biochemistry 47, 8271-8282. doi: 10.1021/ bi 800212 b

Dey, S., Hu, Z., Xu, X. L., Sacchettini, J. C., and Grant, G. A. (2005). D-3Phosphoglycerate dehydrogenase from Mycobacterium tuberculosis is a link between the Escherichia coli and mammalian enzymes. J. Biol. Chem. 280, 14884-14891. doi: 10.1074/jbc.m414488200 
Dong, Y., Silbermann, M., Speiser, A., Forieri, I., Linster, E., Poschet, G., et al. (2017). Sulfur availability regulates plant growth via glucose-TOR signaling. Nat. Commun. 8:1174.

Dowen, R. H., Pelizzola, M., Schmitz, R. J., Lister, R., Dowen, J. M., Nery, J. R., et al. (2012). Widespread dynamic DNA methylation in response to biotic stress. Proc. Natl. Acad. Sci. U.S.A. 109, E2183-E2191.

Droux, M. (2003). Plant serine acetyltransferase: new insights for regulation of sulphur metabolism in plant cells. Plant Physiol. Biochem. 41, 619-627. doi: 10.1016/s0981-9428(03)00083-4

Droux, M., Ruffet, M. L., Douce, R., and Job, D. (1998). Interactions between serine acetyltransferase and $\mathrm{O}$-acetylserine (thiol) lyase in higher plants - Structural and kinetic properties of the free and bound enzymes. Eur. J. Biochem. 255, 235-245. doi: 10.1046/j.1432-1327.1998.2550235.x

Edwards, R. (1996). S-adenosyl-1-methionine metabolism in alfalfa cell cultures following treatment with fungal elicitors. Phytochemistry 43, 1163-1169. doi: 10.1016/S0031-9422(96)00434-7

Engel, N., Ewald, R., Gupta, K. J., Zrenner, R., Hagemann, M., and Bauwe, H. (2011). The presequence of Arabidopsis serine hydroxymethyltransferase SHM2 selectively prevents import into mesophyll mitochondria. Plant Physiol. 157, 1711-1720. doi: 10.1104/pp.111.184564

Engel, N., Van Den Daele, K., Kolukisaoglu, U., Morgenthal, K., Weckwerth, W., Parnik, T., et al. (2007). Deletion of glycine decarboxylase in Arabidopsis is lethal under nonphotorespiratory conditions. Plant Physiol. 144, 1328-1335. doi: 10.1104/pp.107.099317

Espinoza, C., Degenkolbe, T., Caldana, C., Zuther, E., Leisse, A., Willmitzer, L., et al. (2010). Interaction with diurnal and circadian regulation results in dynamic metabolic and transcriptional changes during cold acclimation in Arabidopsis. Plos One 5:e14101. doi: 10.1371/journal.pone.0014101

Flavin, M., and Slaughter, C. (1967). Enzymatic synthesis of homocysteine or methionine directly from O-succinyl-homoserine. Biochim. Biophys. Acta 132, 400-405. doi: 10.1016/0005-2744(67)90158-1

Forieri, I., Sticht, C., Reichelt, M., Gretz, N., Hawkesford, M. J., Malagoli, M., et al. (2017). System analysis of metabolism and the transcriptome in Arabidopsis thaliana roots reveals differential co-regulation upon iron, sulfur and potassium deficiency. Plant, Cell \& Environment 40, 95-107. doi: 10.1111/pce. 12842

Franke, I., Resch, A., Dassler, T., Maier, T., and Bock, A. (2003). YfiK from Escherichia coli promotes export of O-acetylserine and cysteine. J. Bacteriol. 185, 1161-1166. doi: 10.1128/jb.185.4.1161-1166.2003

Galili, G., Amir, R., and Fernie, A. R. (2016). The regulation of essential amino acid synthesis and accumulation in plants. Ann. Rev. Plant Biol 67, 153-178. doi: 10.1146/annurev-arplant-043015-112213

Garcia-Molina, A., Altmann, M., Alkofer, A., Epple, P. M., Dangl, J. L., and Falter-Braun, P. (2017). LSU network hubs integrate abiotic and biotic stress responses via interaction with the superoxide dismutase FSD2. J. Exper. Bot. 68, 1185-1197. doi: 10.1093/jxb/erw498

Gigolashvili, T., Yatusevich, R., Berger, B., Mulle, R. C., and Flugge, U. (2007). The R2R3-MYB transcription factor HAG1/MYB28 is a regulator of methioninederived glucosinolate biosynthesis in Arabidopsis thaliana. Plant J. 51, 247-261. doi: 10.1111/j.1365-313x.2007.03133.x

Gonzalez, B., and Vera, P. (2019). Folate metabolism interferes with plant immunity through 1C methionine synthase-directed genome-wide DNA methylation enhancement. Mol. Plant. 12, 1227-1242. doi: 10.1016/j.molp. 2019.04.013

Gonzalez, M. E., Marco, F., Minguet, E. G., Carrasco-Sorli, P., Blazquez, M. A., Carbonell, J., et al. (2011). Perturbation of spermine synthase gene expression and transcript profiling provide new insights on the role of the tetraamine spermine in Arabidopsis defense against Pseudomonas viridiflava. Plant Physiol. 156, 2266-2277. doi: 10.1104/pp.110.171413

Goto, D. B., Ogi, M., Kijima, F., Kumagai, T., van Werven, F., Onouchi, H., et al. (2002). A single-nucleotide mutation in a gene encoding $S$-adenosylmethionine synthetase is associated with methionine over-accumulation phenotype in Arabidopsis thaliana. Genes Genet. Syst. 77, 89-95. doi: 10.1266/ggs. 77.89

Groppa, M. D., and Benavides, M. P. J. A. A. (2007). Polyamines and abiotic stress: recent advances. Amino Acids 34:35. doi: 10.1007/s00726-007-0501-8
Groth, M., Moissiard, G., Wirtz, M., Wang, H., Garcia-Salinas, C., Ramos-Parra, P. A., et al. (2016). MTHFD1 controls DNA methylation in Arabidopsis. Nat. Commun. 7:11640.

Grundy, F. J., and Henkin, T. M. (1998). The S box regulon: a new global transcription termination control system for methionine and cysteine biosynthesis genes in gram-positive bacteria. Mol. Microbiol. 30, 737-749. doi: 10.1046/j.1365-2958.1998.01105.x

Guranowski, A., and Pawełkiewicz, J. (1977). Adenosylhomocysteinase from yellow lupin seeds. Purification and properties. Eur. J. Biochem. 80, 517-523. doi: 10.1111/j.1432-1033.1977.tb11907.x

Haas, F. H., Heeg, C., Queiroz, R., Bauer, A., Wirtz, M., and Hell, R. (2008). Mitochondrial serine acetyltransferase functions as a pacemaker of cysteine synthesis in plant cells. Plant Physiol. 148, 1055-1067. doi: 10.1104/pp.108. 125237

Hanfrey, C., Sommer, S., Mayer, M. J., Burtin, D., and Michael, A. J. (2001). Arabidopsis polyamine biosynthesis: absence of ornithine decarboxylase and the mechanism of arginine decarboxylase activity. Plant J. 27, 551-560. doi: 10.1046/j.1365-313x.2001.01100.x

Hanson, A. D., and Roje, S. (2001). One-carbon metabolism in higher plants. Ann. Rev. Plant Physiol. Plant Mol. Biol. 52, 119-137.

Hanson, A. D., Gage, D. A., and Shachar-Hill, Y. (2000). Plant one-carbon metabolism and its engineering. Trends Plant Sci. 5, 206-213. doi: 10.1016/ s1360-1385(00)01599-5

Hawkesford, M. J., Schneider, A., Belcher, A. R., and Clarkson, D. T. (1995). Regulation of enzymes involved in the sulphur-assimilatory pathway. Zeitschr. Pflanzenernah. Bodenk. 158, 55-57. doi: 10.1002/jpln.19951580110

He, M. W., Wang, Y., Wu, J. Q., Shu, S., Sun, J., and Guo, S. R. (2019). Isolation and characterization of $S$-adenosylmethionine synthase gene from cucumber and responsive to abiotic stress. Plant Physiol. Biochem. 141, 431-445. doi: 10.1016/j.plaphy.2019.06.006

Heeg, C., Kruse, C., Jost, R., Gutensohn, M., Ruppert, T., Wirtz, M., et al. (2008). Analysis of the Arabidopsis O-acetylserine(thiol)lyase gene family demonstrates compartment-specific differences in the regulation of cysteine synthesis. Plant Cell 20, 168-185. doi: 10.1105/tpc.107.056747

Hesse, H., Trachsel, N., Suter, M., Kopriva, S., Von Ballmoos, P., Rennenberg, H., et al. (2003). Effect of glucose on assimilatory sulphate reduction in Arabidopsis thaliana roots. J. Exper. Bot. 54, 1701-1709. doi: 10.1093/jxb/erg177

Hewezi, T., Lane, T., Piya, S., Rambani, A., Rice, J. H., and Staton, M. (2017). Cyst nematode parasitism induces dynamic changes in the root epigenome. Plant Physiol. 174, 405-420. doi: 10.1104/pp.16.01948

Hindson, V. J. (2003). Serine acetyltransferase of Escherichia coli: substrate specificity and feedback control by cysteine. Biochem. J. 375, 745-752. doi: 10.1042/bj20030429

Hirabayashi, Y., and Furuya, S. (2008). Roles of L-serine and sphingolipid synthesis in brain development and neuronal survival. Prog. Lipid Res. 47, 188-203. doi: 10.1016/j.plipres.2008.01.003

Hirai, M. Y., Fujiwara, T., Awazuhara, M., Kimura, T., Noji, M., and Saito, K. (2003). Global expression profiling of sulfur-starved Arabidopsis by DNA macroarray reveals the role of $\mathrm{O}$-acetyl-L-serine as a general regulator of gene expression in response to sulfur nutrition. Plant J. 33, 651-663. doi: 10.1046/j. 1365-313x.2003.01658.x

Hirai, M. Y., Sugiyama, K., Sawada, Y., Tohge, T., Obayashi, T., Suzuki, A., et al. (2007). Omics-based identification of Arabidopsis Myb transcription factors regulating aliphatic glucosinolate biosynthesis. Proc. Natl Acad. Sci. U.S.A. 104, 6478-6483. doi: 10.1073/pnas.0611629104

Ho, C. L., and Saito, K. (2001). Molecular biology of the plastidic phosphorylated serine biosynthetic pathway in Arabidopsis thaliana. Amino Acids. 20, 243-259. doi: $10.1007 /$ s007260170042

Ho, C. L., Noji, M., and Saito, K. (1999). Plastidic pathway of serine biosynthesis. Molecular cloning and expression of 3-phosphoserine phosphatase from Arabidopsis thaliana. J. Biol. Chem. 274, 11007-11012. doi: 10.1074/jbc.274. 16.11007

Ho, C. L., Noji, M., Saito, M., Yamazaki, M., and Saito, K. (1998). Molecular characterization of plastidic phosphoserine aminotransferase in serine biosynthesis from Arabidopsis. Plant J. 16, 443-452. doi: 10.1046/j.1365313x.1998.00313.x 
Hoffman, D. R., Cornatzer, W. E., and Duerre, J. A. (1979). Relationship between tissue levels of S-adenosylmethionine, S-adenylhomocysteine, and transmethylation reactions. Can. J. Biochem. 57, 56-65. doi: 10.1139/o79-007

Höhner, R., Day, P. M., Zimmermann, S. E., Lopez, L. S., Krämer, M., Giavalisco, P., et al. (2021). Stromal NADH supplied by PHOSPHOGLYCERATE DEHYDROGENASE3 is crucial for photosynthetic performance. Plant Physiol. 13:kiaa117.

Hopkins, L., Parmar, S., Baszczyk, A., Hesse, H., Hoefgen, R., and Hawkesford, M. J. (2005). O-acetylserine and the regulation of expression of genes encoding components for sulfate uptake and assimilation in potato. Plant Physiol. 138, 433-440. doi: 10.1104/pp.104.057521

Howarth, J. R., Barraclough, P. B., and Hawkesford, M. J. (2005). A Highly Specific Sulfate-Deficiency Induced Gene (sdi1) From Wheat. Sulfur Transport and Assimilation in Plants in the Postgenomic Era. Leiden: Backhuys Publishers, 161-164.

Hryniewicz, M. M., and Kredich, N. M. (1994). Stoichiometry of binding of CysB to the cysJIH, cysK, and cysP promoter regions of Salmonella typhimurium. J. Bacteriol. 176, 3673-3682. doi: 10.1128/jb.176.12.3673-3682. 1994

Huang, X. Y., Chao, D. Y., Koprivova, A., Danku, J., Wirtz, M., Muller, S., et al. (2016). Nuclear localised MORE SULPHUR ACCUMULATION1 epigenetically regulates sulphur homeostasis in Arabidopsis thaliana. PLoS Genet. 12:e1006298. doi: 10.1371/journal.pgen.1006298

Hubberten, H. M., Drozd, A., Tran, B. V., Hesse, H., and Hoefgen, R. (2012a). Local and systemic regulation of sulfur homeostasis in roots of Arabidopsis thaliana. Plant J. 72, 625-635. doi: 10.1111/j.1365-313x.2012.05105.x

Hubberten, H. M., Klie, S., Caldana, C., Degenkolbe, T., Willmitzer, L., and Hoefgen, R. (2012b). Additional role of O-acetylserine as a sulfur statusindependent regulator during plant growth. Plant J. 70, 666-677. doi: 10.1111/ j.1365-313x.2012.04905.x

Hulanicka, M. D., Hallquist, S. G., Kredich, N. M., and Mojica, T. (1979). Regulation of O-acetylserine sulfhydrylase B by L-cysteine in Salmonella typhimurium. J. Bacteriol. 140, 141-146. doi: 10.1128/jb.140.1.141-146.1979

Igamberdiev, A. U., and Kleczkowski, L. A. (2018). The glycerate and phosphorylated pathways of serine synthesis in plants: the branches of plant glycolysis linking carbon and nitrogen metabolism. Front. Plant Sci. 14:318. doi: 10.3389/fpls.2018.00318

Ivey, D. M., Guffanti, A. A., Zemsky, J., Pinner, E., Karpel, R., Padan, E., et al. (1993). Cloning and characterization of a putative $\mathrm{Ca} 2+/ \mathrm{H}+$ antiporter gene from Escherichia coli upon functional complementation of $\mathrm{Na}+/ \mathrm{H}+$ antiporterdeficient strains by the overexpressed gene. J. Biolog. Chem. 268, 11296-11303. doi: 10.1016/s0021-9258(18)82124-x

Jakubowski, H. (2000). Homocysteine thiolactone: metabolic origin and protein homocysteinylation in humans. J. Nutr. 130, 377S-381S. doi: 10.1093/jn/130.2. $377 \mathrm{~S}$

Jakubowski, H., and Guranowski, A. (2003). Metabolism of homocysteinethiolactone in plants. J. Biol. Chem. 278, 6765-6770. doi: 10.1074/jbc. $\mathrm{m} 211819200$

Jander, G., and Joshi, V. (2009). Aspartate-derived amino acid biosynthesis in Arabidopsis thaliana. Arabidop. Book 7:e0121. doi: 10.1199/tab.0121

Jiang, C., Belfield, E. J., Cao, Y., Smith, J. A., and Harberd, N. P. (2013). An Arabidopsis soil-salinity-tolerance mutation confers ethylene-mediated enhancement of sodium/potassium homeostasis. Plant Cell 25, 3535-3552. doi: 10.1105/tpc.113.115659

Joshi, N. C., Meyer, A. J., Bangash, S. A. K., Zheng, Z. L., and Leustek, T. (2019). Arabidopsis $\gamma$-glutamylcyclotransferase affects glutathione content and root system architecture during sulfur starvation. New Phytol. 221, 1387-1397. doi: 10.1111/nph.15466

Kawade, K., Horiguchi, G., Oikawa, A., Hirai, M. Y., Saito, K., Fujita, T., et al. (2020). Metabolic control of gametophore shoot formation through arginine in the moss Physcomitrium patens. Cell Rep. 25:5300.

Kawashima, C. G., Berkowitz, O., Hell, R., Noji, M., and Saito, K. (2005). Characterization and expression analysis of a serine acetyltransferase gene family involved in a key step of the sulfur assimilation pathway in Arabidopsis. Plant Physiol. 137, 220-230. doi: 10.1104/pp.104.045377

Kinoshita, T., and Seki, M. (2014). Epigenetic memory for stress response and adaptation in plants. Plant Cell Physiol. 55, 1859-1863. doi: 10.1093/pcp/ pcu 125
Kito, K., Tsutsumi, K., Rai, V., Theerawitaya, C., Cha-Um, S., Yamada-Kato, N., et al. (2017). Isolation and functional characterization of 3-phosphoglycerate dehydrogenase involved in salt responses in sugar beet. Protoplasma 254, 2305-2313. doi: 10.1007/s00709-017-1127-7

Kocsis, M. G., Ranocha, P., Gage, D. A., Simon, E. S., Rhodes, D., Peel, G. J., et al. (2003). Insertional inactivation of the methionine S-methyltransferase gene eliminates the S-methylmethionine cycle and increases the methylation ratio. Plant Physiol. 131, 1808-1815. doi: 10.1104/pp.102.018846

Koffler, B. E., Maier, R., and Zechmann, B. (2011). Subcellular distribution of glutathione precursors in Arabidopsis thaliana. Compartment-specific importance of glutathione during abiotic and biotic stress. J. Integr. Plant Biol. 53, 930-941. doi: 10.1111/j.1744-7909.2011.01085.x

Kopriva, S. (2006). Regulation of sulfate assimilation in Arabidopsis and beyond. Ann. Bot. 97, 479-495. doi: 10.1093/aob/mcl006

Kopriva, S., Suter, M., Von Ballmoos, P., Hesse, H., Krahenbuhl, U., Rennenberg, H., et al. (2002). Interaction of sulfate assimilation with carbon and nitrogen metabolism in Lemna minor. Plant Physiol. 130, 1406-1413. doi: 10.1104/pp. 007773

Koprivova, A., Suter, M., Op Den, Camp, R., Brunold, C., and Kopriva, S. (2000). Regulation of sulfate assimilation by nitrogen in Arabidopsis. Plant Physiol. 122, 737-746. doi: 10.1104/pp.122.3.737

Koronakis, V., Eswaran, J., and Hughes, C. (2004). Structure andfunction of tolC: the bacterial exit duct for proteins and drugs. Ann. Rev. Biochem. 73, 467-489. doi: 10.1146/annurev.biochem.73.011303.074104

Kredich, N. M. (1996). "Biosynthesis of cysteine," in Escherichia coli and Salmonella Typhimurium. Cellular and Molecular Biology, Vol. 1, eds F. C. Neidhardt, R. Curtiss, J. L. Ingraham, E. C. C. Lin, K. B. Low, B. Magasanik, et al. (Washington, DC: American Society for Microbiology), 514-527.

Kredich, N. M., Becker, M. A., and Tomkins, G. M. (1969). Purification and characterization of cysteine synthetase, a bifunctional protein complex, from Salmonella typhimurium. J. Biol. Chem. 244, 2428-2439. doi: 10.1016/s00219258(19)78241-6

Krueger, S., Niehl, A., Lopez Martin, M. C., Steinhauser, D., Donath, A., Hildebrandt, T., et al. (2009). Analysis of cytosolic and plastidic serine acetyltransferase mutants and subcellular metabolite distributions suggests interplay of the cellular compartments for cysteine biosynthesis in Arabidopsis. Plant Cell Environ. 32, 349-367. doi: 10.1111/j.1365-3040.2009.01928.x

Kuhn, A., Engqvist, M. K., Jansen, E. E., Weber, A. P., Jakobs, C., and Maurino, V. G. (2013). D-2-hydroxyglutarate metabolism is linked to photorespiration in the shm1-1 mutant. Plant Biol. 15, 776-784. doi: 10.1111/plb.12020

Kumar, A., Tikoo, S., Maity, S., Sengupta, S., Sengupta, S., Kaur, A., et al. (2012). Mammalian proapoptotic factor $\mathrm{ChaCl}$ and its homologues function as $\gamma$ glutamyl cyclotransferases acting specifically on glutathione. Embo Rep. 13, 1095-1101. doi: 10.1038/embor.2012.156

Kumar, S., Kaur, A., Chattopadhyay, B., and Bachhawat, A. K. (2015). Defining the cytosolic pathway of glutathione degradation in Arabidopsis thaliana: role of the ChaC/GCG family of $\gamma$-glutamyl cyclotransferases as glutathione-degrading enzymes and AtLAP1 as the Cys-Gly peptidase. Biochem. J. 468, 73-85. doi: 10.1042/bj20141154

Lappartient, A. G., Vidmar, J. J., Leustek, T., Glass, A. D. M., and Touraine, B. (1999). Inter-organ signaling in plants: regulation of ATP sulfurylase and sulfate transporter genes expression in roots mediated by phloem-translocated compound. Plant J. 18, 89-95. doi: 10.1046/j.1365-313x.1999.00416.x

Lee, C. P., Wirtz, M., and Hell, R. (2014). Evidence for several cysteine transport mechanisms in the mitochondrial membranes of Arabidopsis thaliana. Plant Cell Physiol. 55, 64-73. doi: 10.1093/pcp/pct155

Le Douce, J., Maugard, M., Veran, J., Matos, M., Jego, P., Vigneron, P. A., et al. (2020). Impairment of glycolysis-derived L-serine production in astrocytes contributes to cognitive deficits in Alzheimer's disease. Cell Metab. 31, 503-517. doi: 10.1016/j.cmet.2020.02.004

Leustek, T., Martin, M. N., Bick, J. A., and Davies, J. P. (2000). Pathways and regulation of sulfur metabolism revealed through molecular and genetic studies. Ann. Rev. Plant Physiol. Plant Mol. Biol. 51, 141-165.

Lewandowska, M., Wawrzynska, A., Kaminska, J., Liszewska, F., and Sirko, A. (2005). Identification of novel genes of Nicotiana tabacum regulated by shortterm sulfur starvation. Sulfur transport and assimilation in plants in the post genomic era. Paper of the 6th International Workshop on Plant Sulfur Metabolism, Chiba, Japan, Chiba, 153. 
Logemann, E., Tavernaro, A., Schulz, W., Somssich, I. E., and Hahlbrock, K. (2000). UV light selectively coinduces supply pathways from primary metabolism and flavonoid secondary product formation in parsley. Proc. Natl. Acad. Sci. USA 97, 1903-1907. doi: 10.1073/pnas.97.4.1903

Lopez-Martin, M. C., Becana, M., Romero, L. C., and Gotor, C. (2008). Knocking out cytosolic cysteine synthesis compromises the antioxidant capacity of the cytosol to maintain discrete concentrations of hydrogen peroxide in Arabidopsis. Plant Physiol. 147, 562-572. doi: 10.1104/pp.108.11 7408

Lynch, A. S., Tyrrell, R., Smerdon, S. J., Briggs, G. S., and Wilkinson, A. J. (1994). Characterization of the CysB protein of Klebsiella aerogenes: direct evidence that $\mathrm{N}$-acetylserine rather than $\mathrm{O}$-acetylserine serves as the inducer of the cysteine regulon. Biochem. J. 299, 129-136. doi: 10.1042/bj2990129

Ma, C., Wang, Y., Gu, D., Nan, J., Chen, S., and Li, H. (2017). Overexpression of $S$-adenosyl-L-methionine synthetase 2 from sugar beet M14 increased Arabidopsis tolerance to salt and oxidative stress. Int. J. Mol. Sci. 18:847. doi: 10.3390/ijms 18040847

Malitsky, S., Blum, E., Less, H., Venger, I., Elbaz, M., Morin, S., et al. (2008). The transcript and metabolite networks affected by the two clades of Arabidopsis glucosinolate biosynthesis regulators. Plant Physiol. 148, 2021-2049. doi: 10. 1104/pp.108.124784

Mao, D., Yu, F., Li, J., Van de Poel, B., Tan, D., Li, J., et al. (2015). FERONIA receptor kinase interacts with S-adenosylmethionine synthetase and suppresses S-adenosylmethionine production and ethylene biosynthesis in Arabidopsis. Plant Cell Environ. 38, 2566-2574. doi: 10.1111/pce.12570

Marco, F., Alcazar, R., Tiburcio, A. F., and Carrasco, P. (2011). Interactions between polyamines and abiotic stress pathway responses unraveled by transcriptome analysis of polyamine overproducers. OMICS 15, 775-781. doi: 10.1089/omi. 2011.0084

Maruyama-Nakashita, A., Inoue, E., Watanabe-Takahashi, A., Yarnaya, T., and Takahashi, H. (2003). Transcriptome profiling of sulfur-responsive genes in Arabidopsis reveals global effects of sulfur nutrition on multiple metabolic pathways. Plant Physiol. 132, 597-605. doi: 10.1104/pp.102.019802

Maruyama-Nakashita, A., Nakamura, Y., Tohge, T., Saito, K., and Takahashi, H. (2006). Arabidopsis SLIM1 is a central transcriptional regulator of plant sulfur response and metabolism. Plant Cell 18, 3235-3251. doi: 10.1105/tpc.106. 046458

Marzluf, G. A. (1997). Molecular genetics of sulfur assimilation in filamentous fungi and yeast. Annu. Rev. Microbiol. 51, 73-96. doi: 10.1146/annurev.micro. 51.1 .73

Mas-Droux, C., Biou, V., and Dumas, R. (2006). Allosteric threonine synthase. Reorganization of the pyridoxal phosphate site upon asym.metric activation through $S$-adenosylmethionine binding to a novel site. J. Biol. Chem. 281, 5188-5196.

Masselot, M., and De Robichon-Szulmajste, H. (1975). Methionine biosynthesis in Saccharomyces cerevisiae. I. Genetical analysis of auxotrophic mutants. Mol. Gen. Genet. 139, 121-132. doi: 10.1007/bf00264692

McClung, C. R., Hsu, M., Painter, J. E., Gagne, J. M., Karlsberg, S. D., and Salome, P. A. (2000). Integrated temporal regulation of the photorespiratory pathway. Circadian regulation of two Arabidopsis genes encoding serine hydroxymethyltransferase. Plant Physiol. 123, 381-391. doi: 10.1104/pp.123. 1.381

Meng, J., Wang, L., Wang, J., Zhao, X., Cheng, J., Yu, W., et al. (2018). METHIONINE ADENOSYLTRANSFERASE4 mediates DNA and histone methylation. Plant Physiol. 177, 652-670. doi: 10.1104/pp.18.00183

Mentch, S. J., Mehrmohamadi, M., Huang, L., Liu, X., Gupta, D., Mattocks, D., et al. (2015). Histone methylation dynamics and gene regulation occur through the sensing of one-carbon metabolism. Cell Metab. 22, 861-873. doi: 10.1016/j. cmet.2015.08.024

Mills, W. R., and Joy, K. W. (1980). A rapid method for isolation of purified, physiologically active chloroplasts, used to study the intracellular distribution of amino acids in pea leaves. Planta 148, 75-83. doi: 10.1007/bf0038 5445

Mino, K., Imamura, K., Sakiyama, T., Eisaki, N., Matsuyama, A., and Nakanishi, K. (2001). Increase in the stability of serine acetyltransferase from Escherichia coli against cold inactivation and proteolysis by forming a bienzyme complex. Biosci. Biotech. Biochem. 65, 865-874. doi: 10.1271/bbb.65.865
Mittal, M., Singh, A. K., and Kumaran, S. (2017). Structural and biochemical characterization of ligand recognition by CysB, the master regulator of sulfate metabolism. Biochimie 142, 112-124. doi: 10.1016/j.biochi.2017.08.011

Moffatt, B. A., and Weretilnyk, E. A. (2001). Sustaining S-adenosyl-L-methioninedependent methyltransferase activity in plant cells. Physiol. Plant. 113, 435-442. doi: 10.1034/j.1399-3054.2001.1130401.x

Moffatt, B. A., Stevens, Y., Allen, M., Snider, J., Pereira, L., Todorova, M., et al. (2002). Adenosine kinase deficiency is associated with developmental abnormalities and reduced transmethylation. Plant Physiol. 128, 812-821. doi: 10.1104/pp.010880

Moniuszko, G., Skoneczny, M., Zientara-Rytter, K., Wawrzynska, A., Glow, D., Cristescu, S. M., et al. (2013). Tobacco LSU-like protein couples sulphurdeficiency response with ethylene signalling pathway. J. Experim. Bot. 64, 5173-5182. doi: 10.1093/jxb/ert309

Mutwil, M., Klie, S., Tohge, T., Giorgi, F. M., Wilkins, O., Campbell, M. M., et al. (2011). PlaNet: combined sequence and expression comparisons across plant networks derived from seven species. Plant Cell 23, 895-910. doi: 10.1105/tpc. 111.083667

Mutwil, M., Obro, J., Willats, W. G. T., and Persson, S. (2008). GeneCAT - novel webtools that combine BLAST and co-expression analyses. Nucleic Acids Res. 36, W320-W326.

Mutwil, M., Usadel, B., Schutte, M., Loraine, A., Ebenhoh, O., and Persson, S. (2010). Assembly of an interactive correlation network for the Arabidopsis genome using a novel heuristic clustering algorithm. Plant Physiol. 152, 29-43. doi: 10.1104/pp.109.145318

Nakamura, T., Iwahashi, H., and Eguchi, Y. (1984). Enzymatic proof for the identity of the S-sulfocysteine synthase and cysteine synthase B of Salmonella typhimurium. J. Bacteriol. 158, 1122-1127. doi: 10.1128/jb.158.3.1122-1127. 1984

Neuenschwander, U., Suter, M., and Brunold, C. (1991). Regulation of sulfate assimilation by light and O-acetyl-1-serine in Lemna minor L. Plant Physiol. 97, 253-258. doi: 10.1104/pp.97.1.253

Nikiforova, V. J., Daub, C. O., Hesse, H., Willmitzer, L., and Hoefgen, R. (2005a). Integrative gene-metabolite network with implemented causality deciphers informational fluxes of sulphur stress response. J. Experim. Bot. 56, 1887-1896. doi: $10.1093 / \mathrm{jxb} / \mathrm{eri1} 19$

Nikiforova, V. J., Kopka, J., Tolstikov, V., Fiehn, O., Hopkins, L., Hawkesford, M. J., et al. (2005b). Systems rebalancing of metabolism in response to sulfur deprivation, as revealed by metabolome analysis of Arabidopsis plants. Plant Physiol. 138, 304-318. doi: 10.1104/pp.104.053793

Nikiforova, V., Freitag, J., Kempa, S., Adamik, M., Hesse, H., and Hoefgen, R. (2003). Transcriptome analysis of sulfur depletion in Arabidopsis thaliana: interlacing of biosynthetic pathways provides response specificity. Plant J. 33, 633-650. doi: 10.1046/j.1365-313x.2003.01657.x

Noji, M., Inoue, K., Kimura, N., Gouda, A., and Saito, K. (1998). Isoformdependent differences in feedback regulation and subcellular localization of serine acetyltransferase involved in cysteine biosynthesis from Arabidopsis thaliana. J. Biolog. Chem. 273, 32739-32745. doi: 10.1074/jbc.273.49.32739

Noji, M., Takagi, Y., Kimura, N., Inoue, K., Saito, M., Horikoshi, M., et al. (2001). Serine acetyltransferase involved in cysteine biosynthesis from spinach: molecular cloning, characterization and expression analysis of cDNA encoding a plastidic isoform. Plant Cell Physiol. 42, 627-634. doi: 10.1093/pcp/pce078

Obayashi, T., Hayashi, S., Saeki, M., Ohta, H., and Kinoshita, K. (2009). ATTEDII provides coexpressed gene networks for Arabidopsis. Nucleic Acids Res. 37, D987-D991.

Obayashi, T., Kinoshita, K., Nakai, K., Shibaoka, M., Hayashi, S., Saeki, M., et al. (2007). ATTED-II: a database of co-expressed genes and cis elements for identifying co-regulated gene groups in Arabidopsis. Nucleic Acids Res. 35, D863-D869.

Okamura, E., and Hirai, M. Y. (2017). Novel regulatory mechanism of serine biosynthesis associated with 3-phosphoglycerate dehydrogenase in Arabidopsis thaliana. Sci. Rep. 7:3533. doi: 10.1038/s41598-017-03807-5

Olsen, L. R., Huang, B., Vetting, M. W., and Roderick, S. L. (2004). Structure of serine acetyltransferase in complexes with CoA and its cysteine feedback inhibitor. Biochemistry 43, 6013-6019. doi: 10.1021/bi0358521

Onouchi, H., Nagami, Y., Haraguchi, Y., Nakamoto, M., Nishimura, Y., Sakurai, R., et al. (2005). Nascent peptide-mediated translation elongation arrest coupled 
with mRNA degradation in the CGS1 gene of Arabidopsis. Genes Dev. 19, 1799-1810. doi: 10.1101/gad.1317105

Onoue, N., Yamashita, Y., Nagao, N., Goto, D. B., Onouchi, H., and Naito, S. (2011). S-adenosyl-L-methionine induces compaction of nascent peptide chain inside the ribosomal exit tunnel upon translation arrest in the Arabidopsis CGS1 gene. J. Biol. Chem. 286, 14903-14912. doi: 10.1074/jbc.M110.211656

Osborne, M. J., Siddiqui, N., Iannuzzi, P., and Gehring, K. (2004). The solution structure of $\mathrm{ChaB}$, a putative membrane ion antiporter regulator from Escherichia coli. BMC Struct. Biol. 4:9.

Ostrowski, J., and Kredich, N. M. (1989). Molecular characterization of the cysJIH promoters of Salmonella typhimurium and Escherichia coli: regulation by cysB protein and N-acetyl-L-serine. J. Bacteriol. 171, 130-140. doi: 10.1128/jb.171.1. 130-140.1989

Ostrowski, J., and Kredich, N. M. (1991). Negative autoregulation of cysB in Salmonella typhimurium: in vitro interactions of CysB protein with the cysB promoter. J. Bacteriol. 173, 2212-2218. doi: 10.1128/jb.173.7.2212-2218.1991

Pajares, M. A., Álvarez, L., and Pérez-Sala, D. (2013). How are mammalian methionine adenosyltransferases regulated in the liver? A focus on redox stress. FEBS Lett. 587, 1711-1716. doi: 10.1016/j.febslet.2013.04.034

Palmieri, L., Arrigoni, R., Blanco, E., Carrari, F., Zanor, M. I., StudartGuimaraes, C., et al. (2006). Molecular identification of an Arabidopsis S-adenosylmethionine transporter. Analysis of organ distribution, bacterial expression, reconstitution into liposomes, and functional characterization. Plant Physiol. 142, 855-865. doi: 10.1104/pp.106.086975

Parry, J., and Clark, D. P. (2002). Identification of a CysB-regulated gene involved in glutathione transport in Escherichia coli. Fems Microbiol. Lett. 209, 81-85. doi: 10.1111/j.1574-6968.2002.tb11113.x

Paulose, B., Chhikara, S., Coomey, J., Jung, H. I., Vatamaniuk, O., and Dhankher, O. P. (2013). A $\gamma$-glutamyl cyclotransferase protects Arabidopsis plants from heavy metal toxicity by recycling glutamate to maintain glutathione homeostasis. Plant Cell 25, 4580-4595. doi: 10.1105/tpc.113.111815

Peng, J., Li, Z., Wen, X., Li, W., Shi, H., Yang, L., et al. (2014). Saltinduced stabilization of EIN3/EIL1 confers salinity tolerance by deterring ROS accumulation in Arabidopsis. PLoS Genet. 10:e1004664. doi: 10.1371/journal. pgen.1004664

Pereira, L. A. R., Todorova, M., Cai, X., Makaroff, C. A., Emery, R. J. N., and Moffatt, B. A. (2007). Methyl recycling activities are co-ordinately regulated during plant development. J. Exp. Bot. 58, 1083-1098. doi: 10.1093/jxb/erl275

Pick, T. R., Bräutigam, A., Schulz, M. A., Obata, T., Fernie, A. R., and Weber, A. P. (2013). PLGG1, a plastidic glycolate glycerate transporter, is required for photorespiration and defines a unique class of metabolite transporters. Proc. Natl. Acad. Sci. U.S.A. 110, 3185-3190. doi: 10.1073/pnas.1215142110

Pizer, L. I. (1963). The pathway and control of serine biosynthesis in Escherichia Coli. J. Biol. Chem. 238, 3934-3944. doi: 10.1016/s0021-9258(18)51809-3

Poloni, S., Blom, H. J., and Schwartz, I. V. D. (2015). Stearoyl-CoA desaturase-1: is it the link between sulfur amino acids and lipid metabolism? Biology (Basel) 4 , 383-396. doi: 10.3390/biology4020383

Pommerrenig, B., Feussner, K., Zierer, W., Rabinovych, V., Klebl, F., Feussner, I., et al. (2011). Phloem-specific expression of Yang cycle genes and identification of novel Yang cycle enzymes in Plantago and Arabidopsis. Plant Cell 23, 1904-1919. doi: $10.1105 /$ tpc. 110.079657

Qi, J., Song, C. P., Wang, B., Zhou, J., Kangasjarvi, J., Zhu, J. K., et al. (2018). Reactive oxygen species signaling and stomatal movement in plant responses to drought stress and pathogen attack. J. Integr. Plant Biol. 60, 805-826. doi: 10.1111/jipb. 12654

Ravanel, S., Block, M. A., Rippert, P., Jabrin, S., Curien, G., Rébeillé, F., et al. (2004). Methionine metabolism in plants. J. Biol. Chem. 279, 22548-22557. doi: 10.1074/jbc.m313250200

Rocha, P. S. C. F., Sheikh, M., Melchiorre, R., Fagard, M., Boutet, S., Loach, R., et al. (2005). The Arabidopsis HOMOLOGY-DEPENDENT GENE SILENCING1 gene codes for an S-adenosyl-L-homocysteine hydrolase required for DNA methylation-dependent gene silencing. Plant Cell. 17, 404-417. doi: 10.1105/ tpc. 104.028332

Ros, R., Munoz-Bertomeu, J., and Krueger, S. (2014). Serine in plants: biosynthesis, metabolism, and functions. Trends Plant Sci. 19, 564-569. doi: 10.1016/j. tplants.2014.06.003

Rosa-Tellez, S., Anoman, A. D., Alcantara-Enguidanos, A., Garza-Aguirre, R. A., Alseekh, S., and Ros, R. (2020). PGDH family genes differentially affect
Arabidopsis tolerance to salt stress. Plant Sci. 290:110284. doi: 10.1016/j. plantsci.2019.110284

Rouached, H., Wirtz, M., Alary, R., Hell, R., Arpat, A. B., Davidian, J. C., et al. (2008). Differential regulation of the expression of two high-affinity sulfate transporters, SULTR1.1 and SULTR1.2, in Arabidopsis. Plant Physiol. 147, 897-911. doi: 10.1104/pp.108.118612

Roy, M., and $\mathrm{Wu}$, R. (2002). Overexpression of S-adenosylmethionine decarboxylase gene in rice increases polyamine level and enhances sodium chloride-stress tolerance. Plant Sci. 163, 987-992. doi: 10.1016/S0168-9452(02) 00272-8

Ruffet, M. L., Lebrun, M., Droux, M., and Douce, R. (1995). Subcellular distribution of serine acetyltransferase from Pisum sativum and characterization of an Arabidopsis thaliana putative cytosolic isoform. Eur. J. Biochem. 227, 500-509. doi: 10.1111/j.1432-1033.1995.tb20416.x

Ruszkowski, M., Sekula, B., Ruszkowska, A., and Dauter, Z. (2018). Chloroplastic serine hydroxymethyltransferase from Medicago truncatula: a structural characterization. Front. Plant Sci. 9:584. doi: 10.3389/fpls.2018.00584

Saito, K. (2004). Sulfur assimilatory metabolism. The long and smelling road. Plant Physiol. 136, 2443-2450. doi: 10.1104/pp.104.046755

Saito, K., Yokoyama, H., Noji, M., and Murakoshi, I. (1995). Molecular cloning and characterization of a plant serine acetyltransferase playing a regulatory role in cysteine biosynthesis from watermelon. J. Biolog. Chem. 270, 16321-16326. doi: $10.1074 /$ jbc.270.27.16321

Samuilov, S., Brilhaus, D., Rademacher, N., Flachbart, S., Arab, L., Alfarraj, S., et al. (2018). The photorespiratory BOU gene mutation alters sulfur assimilation and its crosstalk with carbon and nitrogen metabolism in Arabidopsis thaliana. Front Plant Sci. 9:1709.

Sánchez-Aguayo, I., Rodríguez-Galán, J. M., García, R., Torreblanca, J., and Pardo, J. M. (2004). Salt stress enhances xylem development and expression of S-adenosyl-L-methionine synthase in lignifying tissues of tomato plants. Planta 220, 278-285. doi: 10.1007/s00425-004-1350-2

Sauter, M., Moffatt, B., Saechao, M. C., Hell, R., and Wirtz, M. (2013). Methionine salvage and S-adenosylmethionine: essential links between sulfur, ethylene and polyamine biosynthesis. Biochem. J. 451, 145-154. doi: 10.1042/bj20121744

Sekowska, A., Ashida, H., and Danchin, A. (2019). Revisiting the methionine salvage pathway and its paralogues. Microb. Biotechnol. 12, 77-97. doi: 10.1111/ 1751-7915.13324

Sekowska, A., Kung, H. F., and Danchin, A. (2000). Sulfur metabolism in Escherichia coli and related bacteria: facts and fiction. J. Mol. Microbiol. Biotech. 2, 145-177.

Shiraki, N., Shiraki, Y., Tsuyama, T., Obata, F., Miura, M., Nagae, G., et al. (2014). Methionine metabolism regulates maintenance and differentiation of human pluripotent stem cells. Cell Metab. 19, 780-794. doi: 10.1016/j.cmet.2014.03.017

Shyh-Chang, N., Locasale, J. W., Lyssiotis, C. A., Zheng, Y., Teo, R. Y., Ratanasirintrawoot, S., et al. (2013). Influence of threonine metabolism on S-adenosylmethionine and histone methylation. Science 339, 222-226. doi: 10. $1126 /$ science. 1226603

Sirko, A., Wawrzynska, A., Rodriguez, M. C., and Sektas, P. (2015). The family of LSU-like proteins. Front. Plant Sci. 5:774.

Smith, I. K. (1972). Studies of l-cysteine biosynthetic enzymes in Phaseolus vulgaris L. Plant Physiol. 50, 477-479. doi: 10.1104/pp.50.4.477

Sønderby, I. E., Hansen, B. G., Bjarnholt, N., Halkier, B. A., and Kliebenstein, D. J. (2007). A systems biology approach identifies a R2R3 MYB gene subfamily with distinct and overlapping functions in regulation of aliphatic glucosinolates. PLoS One 2:e1322. doi: 10.1371/journal.pone.0001322

South, P. F., Walker, B. J., Cavanagh, A. P., Rolland, V., Badger, M., and Ort, D. R. (2017). Bile acid sodium symporter BASS6 can transport glycolate and is involved in photorespiratory metabolism in Arabidopsis thaliana. Plant Cell 29, 808-823. doi: $10.1105 /$ tpc. 16.00775

Takahashi, H., Kopriva, S., Giordano, M., Saito, K., and Hell, R. (2011). Sulfur assimilation in photosynthetic organisms: molecular functions and regulations of transporters and assimilatory enzymes. Ann. Rev. Plant Biol. 62, 157-184. doi: 10.1146/annurev-arplant-042110-103921

Takahashi, M., Terada, Y., Nakai, I., Nakanishi, H., Yoshimura, E., Mori, S., et al. (2003). Role of nicotianamine in the intracellular delivery of metals and plant reproductive development. Plant Cell. 15, 1263-1280. doi: 10.1105/tpc.010256

Tehlivets, O., Malanovic, N., Visram, M., Pavkov-Keller, T., and Keller, M. (2013). S-adenosyl-L-homocysteine hydrolase and methylation disorders: yeast as a 
model system. Biochim. Biophys. Acta. 1832, 204-215. doi: 10.1016/j.bbadis. 2012.09.007

Toujani, W., Munoz-Bertomeu, J., Flores-Tornero, M., Rosa-Tellez, S., Anoman, A. D., Alseekh, S., et al. (2013a). Functional characterization of the plastidial 3-phosphoglycerate dehydrogenase family in Arabidopsis. Plant Physiol. 163, 1164-1178. doi: 10.1104/pp.113.226720

Toujani, W., Munoz-Bertomeu, J., Flores-Tornero, M., Rosa-Tellez, S., Anoman, A., and Ros, R. (2013b). Identification of the phosphoglycerate dehydrogenase isoform EDA9 as the essential gene for embryo and male gametophyte development in Arabidopsis. Plant Signal Behav. 8:e27207. doi: 10.4161/psb. 27207

Ulanovskaya, O. A., Zuhl, A. M., and Cravatt, B. F. (2013). NNMT promotes epigenetic remodeling in cancer by creating a metabolic methylation sink. Nat. Chem. Biol. 9, 300-306. doi: 10.1038/nchembio.1204

Urano, Y., Manabe, T., Noji, M., and Saito, K. (2000). Molecular cloning and functional characterization of cDNAs encoding cysteine synthase and serine acetyltransferase that may be responsible for high cellular cysteine content in Allium tuberosum. Gene 257, 269-277. doi: 10.1016/s0378-1119(00)00399-1

Ushijima, T., Hanada, K., Gotoh, E., Yamori, W., Kodama, Y., Tanaka, H., et al. (2017). Light controls protein localization through phytochrome-mediated alternative promoter selection. Cell 171, 1316-1325.e12..

Van Der Ploeg, J. R., Eichhorn, E., and Leisinger, T. (2001). Sulfonate-sulfur metabolism and its regulation in Escherichia coli. Arch. Microbiol. 176, 1-8. doi: 10.1007/s002030100298

Vandekeere, S., Dubois, C., Kalucka, J., Sullivan, M. R., García-Caballero, M., Goveia, J., et al. (2018). Serine synthesis via PHGDH is essential for heme production in endothelial cells. Cell Metab. 28, 573-587. doi: 10.1016/j.cmet. 2018.06.009

Vandereyken, K., Van Leene, J., De Coninck, B., and Cammue, B. P. A. (2018). Hub protein controversy: taking a closer look at plant stress response hubs. Front. Plant Sci. 9:694.

Vandrisse, C. M., and Escalante-Semerena, J. C. (2018). In Salmonella enterica, OatA (formerly YjgM) uses O-acetyl-serine and acetyl-CoA to synthesize N,O-Diacetylserine, which upregulates cysteine biosynthesis. Front. Microbiol. 9:2838.

Vauclare, P., Kopriva, S., Fell, D., Suter, M., Sticher, L., Von Ballmoos, P., et al. (2002). Flux control of sulphate assimilation in Arabidopsis thaliana: adenosine $5^{\prime}$-phosphosulphate reductase is more susceptible than ATP sulphurylase to negative control by thiols. Plant J. 31, 729-740. doi: 10.1046/j.1365-313x.2002. 01391.x

Voll, L. M., Jamai, A., Renne, P., Voll, H., Mcclung, C. R., and Weber, A. P. M. (2006). The photorespiratory Arabidopsis shm 1 mutant is deficient in SHM1. Plant Physiol. 140, 59-66. doi: 10.1104/pp.105.071399

Waie, B., and Rajam, M. V. (2003). Effect of increased polyamine biosynthesis on stress responses in transgenic tobacco by introduction of human S-adenosylmethionine gene. Plant Sci. 164, 727-734. doi: 10.1016/S01689452(03)00030-X

Wang, T., and Leyh, T. S. (2012). Three-stage assembly of the cysteine synthase complex from Escherichia coli. J. Biolog. Chem. 287, 4360-4367. doi: 10.1074/ jbc.m111.288423

Watanabe, M., Kusano, M., Oikawa, A., Fukushima, A., Noji, M., and Saito, K. (2008a). Physiological roles of the $\beta$-substituted alanine synthase gene family in Arabidopsis. Plant Physiol. 146, 310-320. doi: 10.1104/pp.107.106831

Watanabe, M., Mochida, K., Kato, T., Tabata, S., Yoshimoto, N., Noji, M., et al. (2008b). Comparative genomics and reverse genetics analysis reveal indispensable functions of the serine acetyltransferase gene family in Arabidopsis. Plant Cell 20, 2484-2496. doi: 10.1105/tpc.108.060335

Watanabe, M., Tohge, T., Fernie, A. R., and Hoefgen, R. (2018). The effect of single and multiple SERAT mutants on serine and sulfur metabolism. Front. Plant Sci. 9:702.

Wawrzynska, A., Lewandowska, M., and Sirko, A. (2010). Nicotiana tabacum EIL2 directly regulates expression of at least one tobacco gene induced by sulphur starvation. J. Experim. Bot. 61, 889-900. doi: 10.1093/jxb/erp356

Wawrzynska, A., Lewandowska, M., Hawkesford, M. J., and Sirko, A. (2005). Using a suppression subtractive library-based approach to identify tobacco genes regulated in response to short-term sulphur deficit. J. Experim. Bot. 56, 1575-1590. doi: $10.1093 / \mathrm{jxb} / \mathrm{eri152}$

Weretilnyk, E. A., Alexander, K. J., Drebenstedt, M., Snider, J. D., Summers, P. S., and Moffatt, B. (2001). Maintaining methylation activities during salt stress: the involvement of adenosine kinase. Plant Physiol. 125, 856-865. doi: 10.1104/pp. 125.2.856

Westerman, S., Stulen, I., Suter, M., Brunold, C., and De Kok, L. J. (2001). Atmospheric $\mathrm{H}_{2} \mathrm{~S}$ as sulphur source for Brassica oleracea: consequences for the activity of the enzymes of the assimilatory sulphate reduction pathway. Plant Physiol. Biochem. 39, 425-432. doi: 10.1016/s0981-9428(01)01 258-x

Wirtz, M., Beard, K. F., Lee, C. P., Boltz, A., Schwarzländer, M., Fuchs, C., et al. (2012). Mitochondrial cysteine synthase complex regulates O-acetylserine biosynthesis in plants. J. Biol. Chem. 287, 27941-27947. doi: 10.1074/jbc.m112. 372656

Wirtz, M., Berkowitz, O., Droux, M., and Hell, R. (2001). The cysteine synthase complex from plants - Mitochondrial serine acetyltransferase from Arabidopsis thaliana carries a bifunctional domain for catalysis and protein-protein interaction. Eur. J. Biochem. 268, 686-693. doi: 10.1046/j.1432-1327.2001. 01920.x

Wirtz, M., Birke, H., Heeg, C., Muller, C., Hosp, F., Throm, C., et al. (2010). Structure and function of the hetero-oligomeric cysteine synthase complex in plants. J. Biolog. Chem. 285, 32810-32817. doi: 10.1074/jbc.m110.15 7446

Wulfert, S., and Krueger, S. (2018). Phosphoserine aminotransferase1 is part of the phosphorylated pathways for serine biosynthesis and essential for light and sugar-dependent growth promotion. Front. Plant Sci. 9:1712.

Xu, R., Wang, Y., Zheng, H., Lu, W., Wu, C., Huang, J., et al. (2015). Salt-induced transcription factor MYB74 is regulated by the RNA-directed DNA methylation pathway in Arabidopsis. J. Exp. Bot. 66, 5997-6008. doi: 10.1093/jxb/erv312

Yamada, S., Awano, N., Inubushi, K., Maeda, E., Nakamori, S., Nishino, K., et al. (2006). Effect of drug transporter genes on cysteine export and overproduction in Escherichia coli. App. Environ. Microbiol. 72, 4735-4742. doi: 10.1128/aem. 02507-05

Yamaguchi, K., Takahashi, Y., Berberich, T., Imai, A., Miyazaki, A., Takahashi, T., et al. (2006). The polyamine spermine protects against high salt stress in Arabidopsis thaliana. FEBS Lett. 580, 6783-6788. doi: 10.1016/j.febslet.2006.10. 078

Yamaguchi, K., Takahashi, Y., Berberich, T., Imai, A., Takahashi, T., Michael, A. J., et al. (2007). A protective role for the polyamine spermine against drought stress in Arabidopsis. Biochem. Biophys. Res. Commun. 352, 486-490. doi: 10.1016/j. bbrc.2006.11.041

Yong-Villalobos, L., González-Morales, S. I., Wrobel, K., Gutiérrez-Alanis, D., Cervantes-Peréz, S. A., Hayano-Kanashiro, C., et al. (2015). Methylome analysis reveals an important role for epigenetic changes in the regulation of the Arabidopsis response to phosphate starvation. Proc. Natl. Acad. Sci. U.S.A. 112, E7293-E7302.

Yoshida, K., Ohtaka, K., Hirai, M. Y., and Hisabori, T. (2020). Biochemical insight into redox regulation of plastidial 3-phosphoglycerate dehydrogenase from Arabidopsis thaliana. J. Biol. Chem. 295, 14906-14915. doi: 10.1074/jbc.ra120. 014263

Zhang, B., Tieman, D. M., Jiao, C., Xu, Y., Chen, K., Fe, Z., et al. (2016). Chillinginduced tomato flavor loss is associated with altered volatile synthesis and transient changes in DNA methylation. Proc. Natl. Acad. Sci. U.S.A. 113, 15580-12585.

Zhang, Y., Sun, K. H., Sandoval, F. J., Santiago, K., and Roje, S. (2010). One-carbon metabolism in plants: characterization of a plastid serine hydroxymethyltransferase. Biochem. J. 430, 97-105. doi: 10.1042/bj20100566

Zientara-Rytter, K., Lukomska, J., Moniuszko, G., Gwozdecki, R., Surowiecki, P., Lewandowska, M., et al. (2011). Identification and functional analysis of Joka2, a tobacco member of the family of selective autophagy cargo receptors. Autophagy 7, 1145-1158. doi: 10.4161/auto.7.10.16617

Conflict of Interest: The authors declare that the research was conducted in the absence of any commercial or financial relationships that could be construed as a potential conflict of interest.

Copyright (c) 2021 Watanabe, Chiba and Hirai. This is an open-access article distributed under the terms of the Creative Commons Attribution License (CC BY). The use, distribution or reproduction in other forums is permitted, provided the original author(s) and the copyright owner(s) are credited and that the original publication in this journal is cited, in accordance with accepted academic practice. No use, distribution or reproduction is permitted which does not comply with these terms. 